\title{
Co(II) macrocyclic complexes appended with fluorophores as paraCEST and
}

\section{cellCEST agents}

Akanksha Patel ${ }^{1}$, Samira M. Abozeid ${ }^{1}$, Paul J. Cullen ${ }^{2}$ and Janet R. Morrow ${ }^{1 *}$

1. Department of Chemistry, University at Buffalo, State University of New York, Amherst, NY 14260

2. Department of Biological Sciences, University at Buffalo, State University of New York, Amherst, NY 14260

\section{Contents}

Synthesis

S2-S3

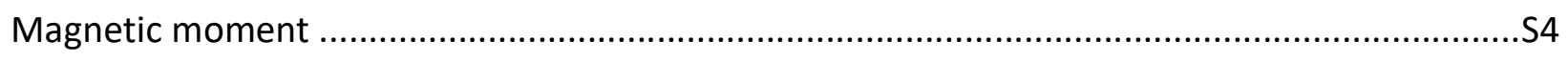

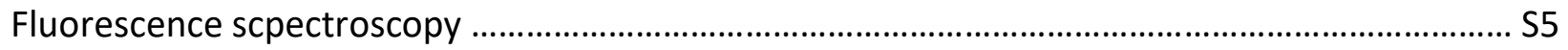

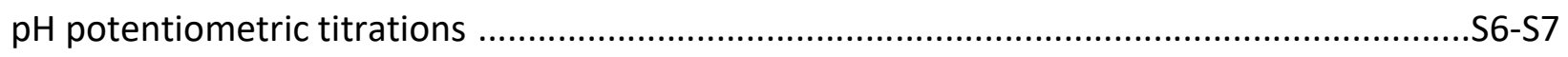

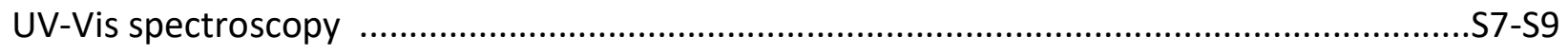

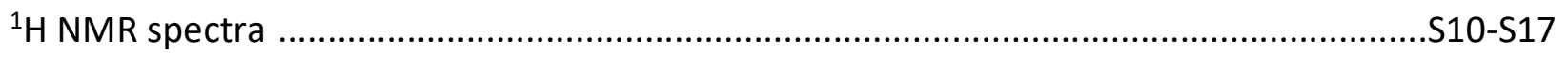

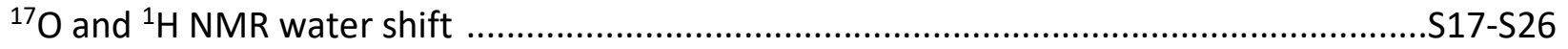

Chemical Exchange Saturation Transfer (CEST) ..........................................................S26-S31

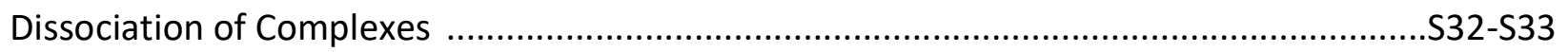

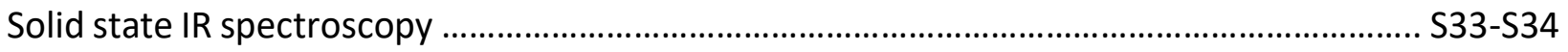

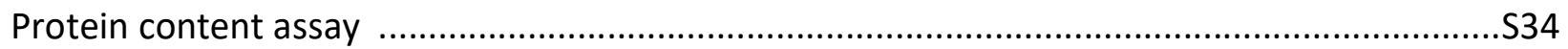

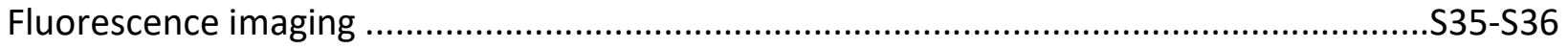

Cell viability assay on Co(II)-complex labeled yeast ........................................................536 


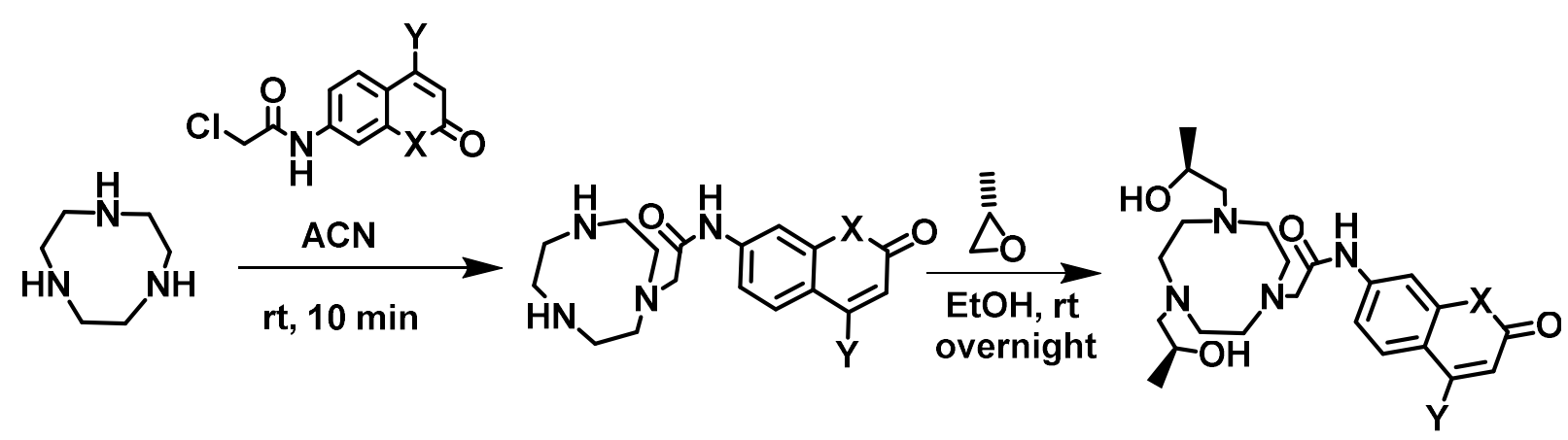

$\mathrm{X}=\mathrm{NH} ; \mathrm{Y}=\mathrm{CH}_{3}$ TACN-Cs

$\mathrm{X}=\mathrm{O} ; \mathrm{Y}=\mathrm{CH}_{3}$ TACN-Cou121

$\mathrm{X}=\mathrm{O} ; \mathrm{Y}=\mathrm{CF}_{3}$ TACN-Cou151
$X=\mathrm{NH} ; \mathrm{Y}=\mathrm{CH}_{3}$ TOCs

$\mathrm{X}=\mathrm{O} ; \mathrm{Y}=\mathrm{CH}_{3}$ TOCO121

$\mathrm{X}=\mathrm{O} ; \mathrm{Y}=\mathrm{CF}_{3}$ TOCO151<smiles></smiles>

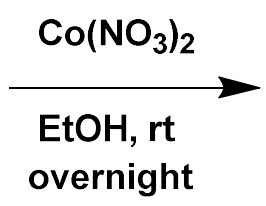

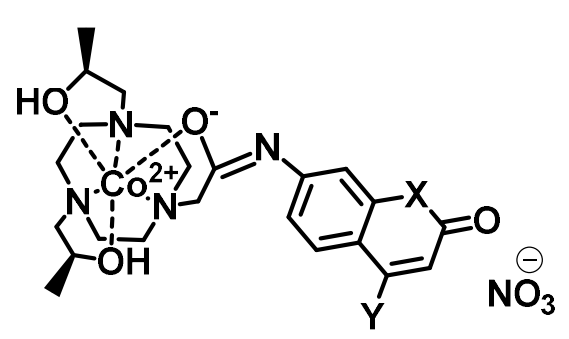

$\mathrm{X}=\mathrm{NH} ; \mathrm{Y}=\mathrm{CH}_{3}\left[\mathrm{Co}\left(\mathrm{TOCs}-\mathrm{H}^{+}\right)\right]\left(\mathrm{NO}_{3}\right)$

$\mathrm{X}=\mathrm{O} ; \mathrm{Y}=\mathrm{CH}_{3}\left[\mathrm{Co}\left(\mathrm{TOCO} 121-\mathrm{H}^{+}\right)\right]\left(\mathrm{NO}_{3}\right)$

$\mathrm{X}=\mathrm{O} ; \mathrm{Y}=\mathrm{CF}_{3}\left[\mathrm{Co}\left(\mathrm{TOCO} 151-\mathrm{H}^{+}\right)\right]\left(\mathrm{NO}_{3}\right)$

Scheme S1. Synthesis of Co(II) based complexes. 


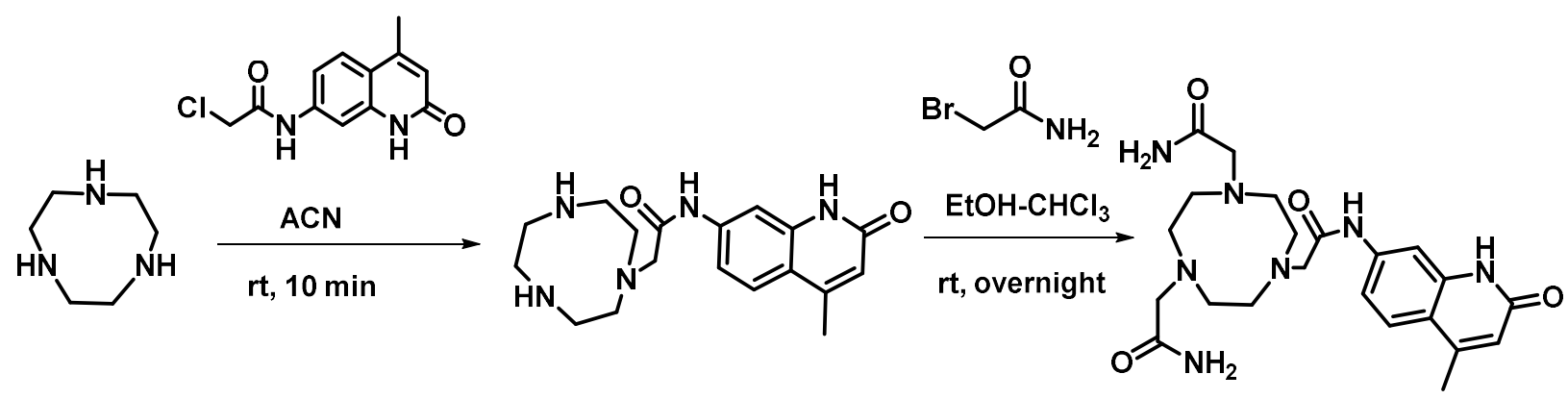

TACN-Cs

TACs<smiles></smiles><smiles>CCOC(=O)ON(C)C(=O)OC</smiles>

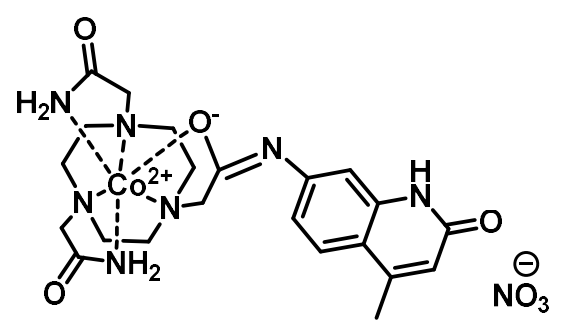

$\left[\mathrm{Co}\left(\mathrm{TACs}-\mathrm{H}^{+}\right)\right]\left(\mathrm{NO}_{3}\right)$

Scheme S2. Synthesis of $\left[\mathrm{Co}\left(\mathrm{TACs}-\mathrm{H}^{+}\right)\right]\left(\mathrm{NO}_{3}\right)$ based complexes.

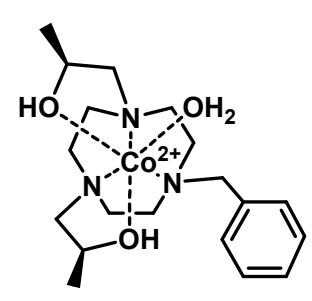

Co(TOB)

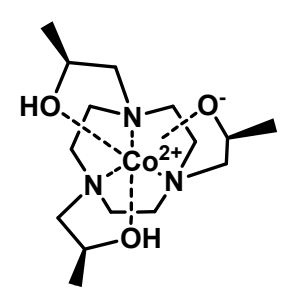

Co(TOT)
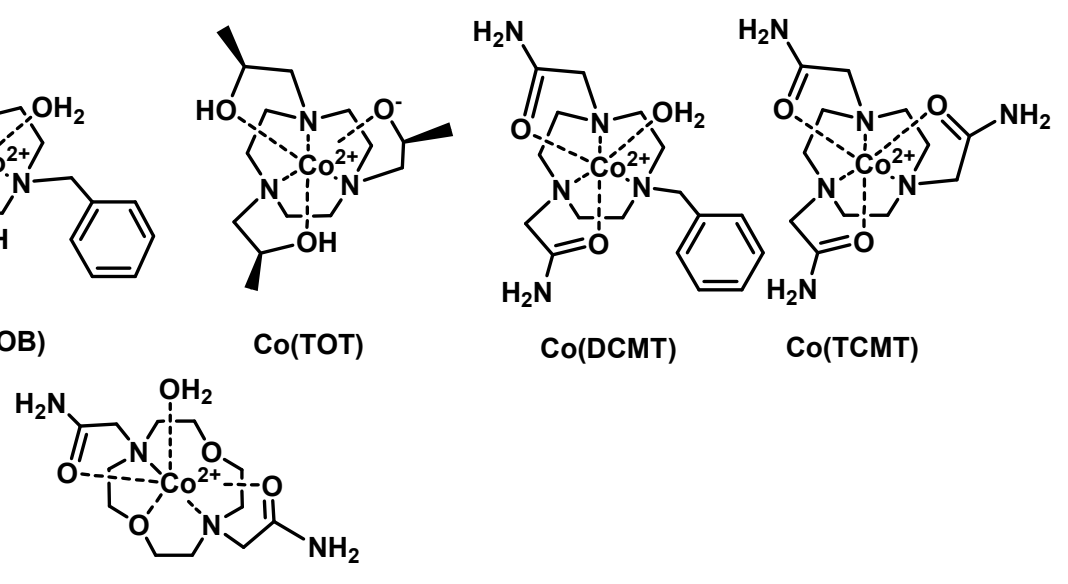

Co(NODA)

Scheme S3. Related Co(II) complexes. Species shown for neutral pH 
Table S1. Effective magnetic moment values through Evan's method for Cobalt complexes.

\begin{tabular}{|cc|}
\hline Complex & $\begin{array}{c}\text { Effective magnetic } \\
\text { moment }\end{array}$ \\
\hline CoTOCO151 & 4.38 \\
\hline CoTOCs & 4.23 \\
\hline CoTOCO121 & 4.46 \\
\hline CoTACs & 4.30 \\
\hline
\end{tabular}


(a)

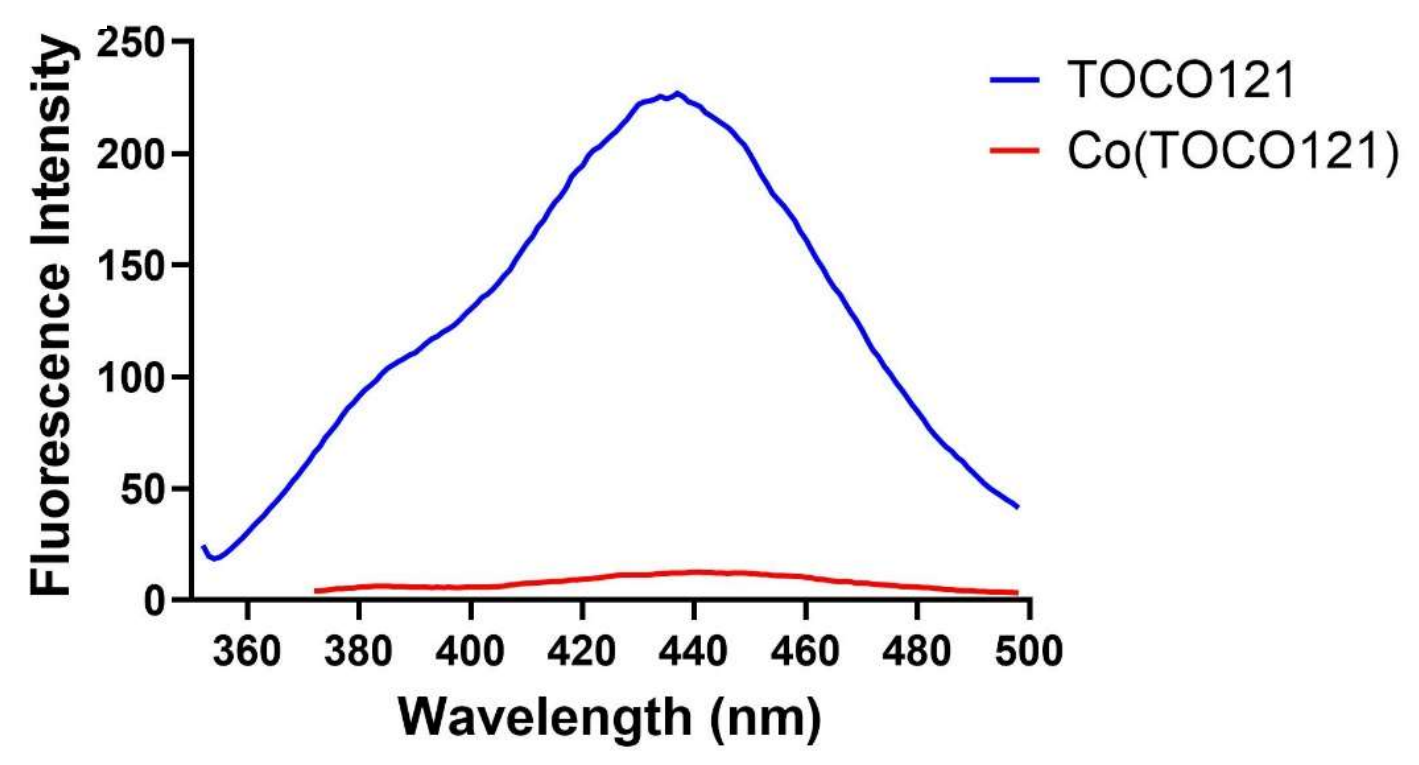

(b)

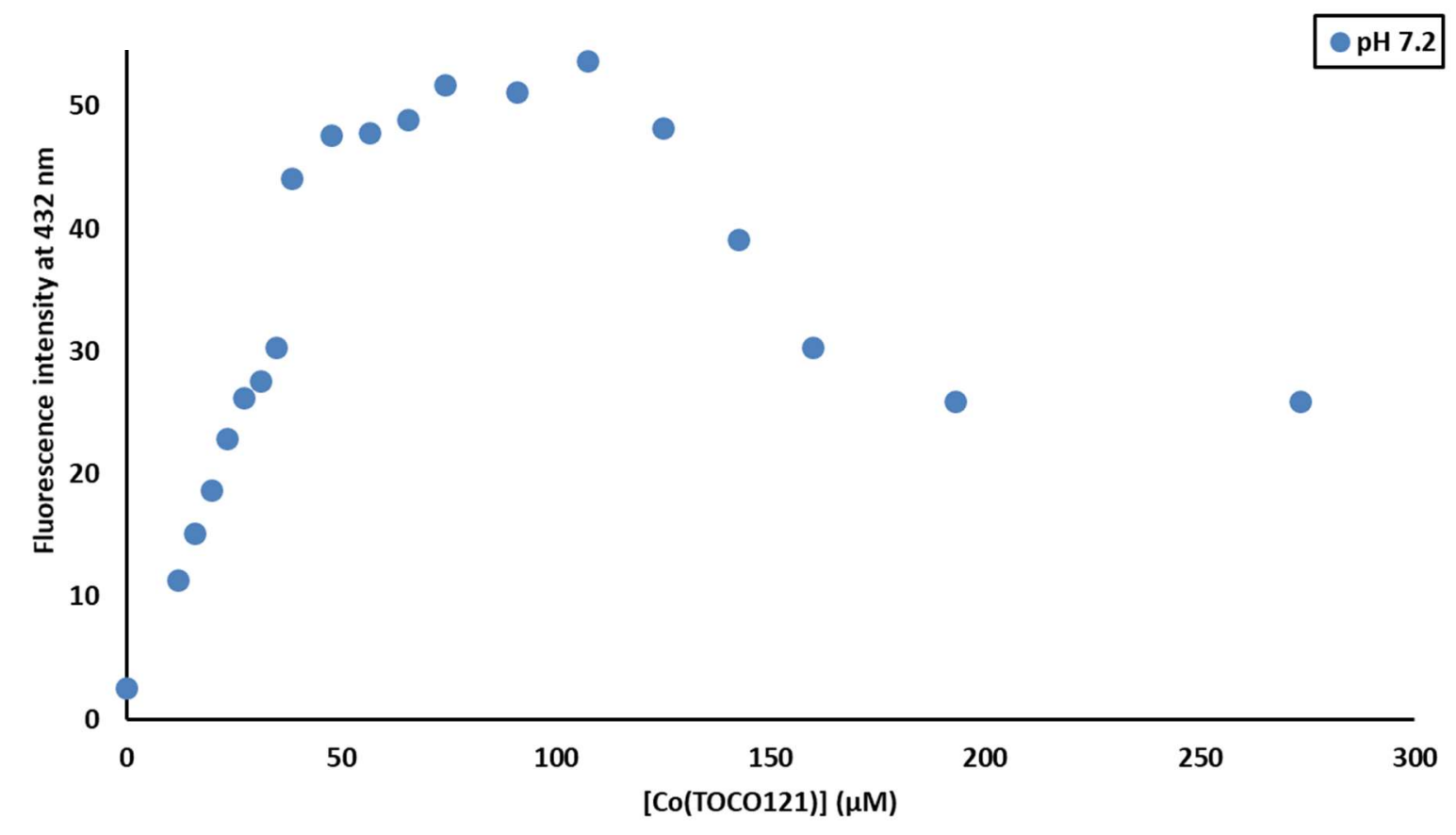

Figure S1 (a) Graph of fluorescence emission of $10 \mu \mathrm{M}$ TOCO121 ligand and 10 $\mu \mathrm{M}$ Co(TOCO121) complex with $\lambda_{\text {ex }}=345 \mathrm{~nm}$ in $20 \mathrm{mM} \mathrm{HEPES}$ buffer pH 7.2 and $100 \mathrm{mM} \mathrm{NaCl}$. The fluorescence emission is highly quenched in the $\mathrm{Co}(\mathrm{II})$ complex. (b) Variation of fluorescence intensity of [Co(TOCO121)] with concentration at $432 \mathrm{~nm}$ at $\mathrm{pH} 7.2, \lambda_{\mathrm{ex}}=345 \mathrm{~nm}$. 
Table S2. Equilibrium expressions and constants. Equations refer to the ionization of the Co(TOCS) or Co(TOCO) complexes as shown in Scheme 1. Not all compound exhibit all the equilibria shown. $\mathrm{A}=\left[\mathrm{Co}\left(\mathrm{TOCs}-3 \mathrm{H}^{+}\right)\right]^{-}$or $\left[\mathrm{Co}\left(\mathrm{TOCO} 121-2 \mathrm{H}^{+}\right)\right]$

\begin{tabular}{|c|c|c|}
\hline Eq. 1 & $\mathrm{A}+\mathrm{H}^{+} \rightleftharpoons \mathrm{AH}$ & $\mathrm{K}_{1}=\frac{[\mathrm{AH}]}{[\mathrm{A}]\left[\mathrm{H}^{+}\right]}$ \\
\hline Eq. 2 & $\mathrm{AH}+\mathrm{H}^{+} \rightleftharpoons \mathrm{AH}_{2}$ & $\mathrm{~K}_{2}=\frac{\left[\mathrm{AH}{ }_{2}\right]}{[\mathrm{AH}]\left[\mathrm{H}^{+}\right]}$ \\
\hline Eq. 3 & $\mathrm{AH}_{2}+\mathrm{H}^{+} \rightleftharpoons \mathrm{AH}_{3}$ & $\mathrm{~K}_{2}=\frac{\left[\mathrm{AH}_{3}\right]}{\left[\mathrm{AH}_{2}\right]\left[\mathrm{H}^{+}\right]}$ \\
\hline
\end{tabular}

Table S3. Equilibrium constants from potentiometric titrations at $25^{\circ} \mathrm{C}$, in $0.10 \mathrm{M} \mathrm{NaCl}$.

\begin{tabular}{|c|c|c|}
\hline Equilibria & Co(TOCs) & Co(TOCO121) \\
\hline Log $K_{1}$ & $10.40 \pm 0.027$ & $10.0 \pm 0.07$ \\
\hline $\log K_{2}$ & $6.70 \pm 0.040$ & $5.90 \pm 0.11$ \\
\hline $\log K_{3}$ & $5.90 \pm 0.038$ & $\ldots .$. \\
\hline
\end{tabular}
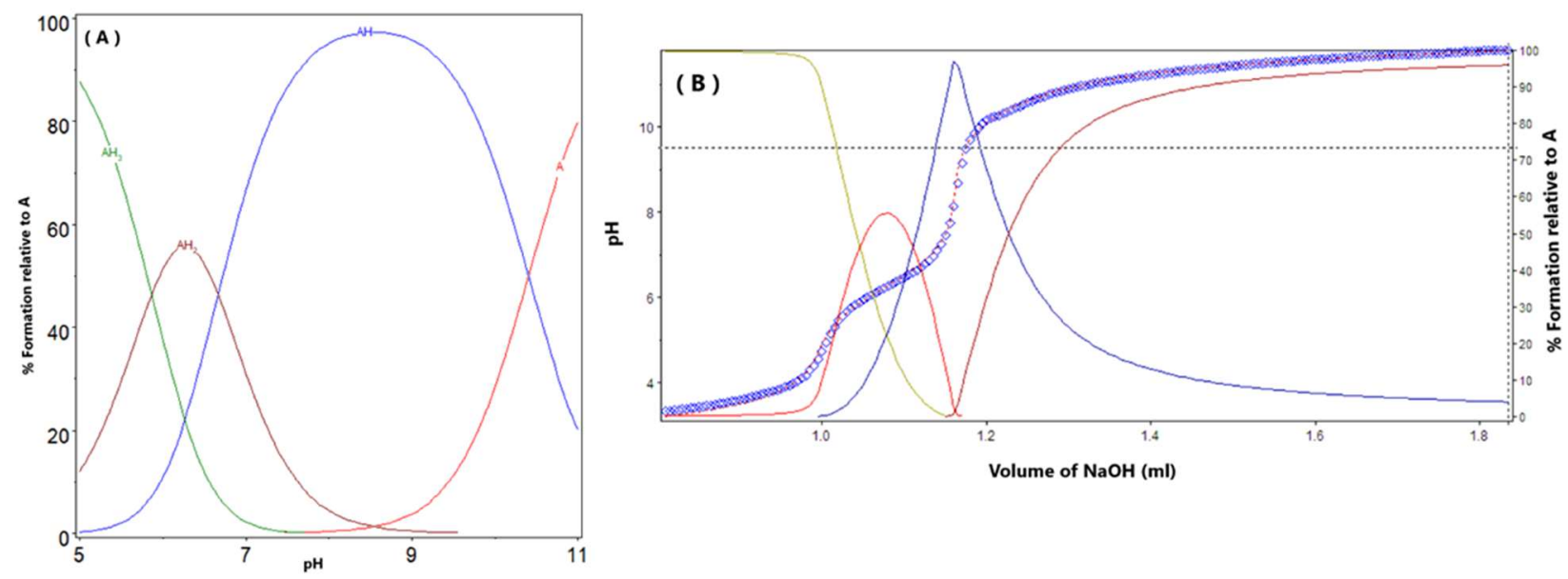

Figure S2. Speciation diagram (A) derived from potentiometric data (B) to represent a solution containing $1 \mathrm{mM} \mathrm{Co}$ (TOCs) in $0.1 \mathrm{M} \mathrm{NaCl}$ at $25^{\circ} \mathrm{C}$. A represents the deprotonated complex $\left[\mathrm{Co}\left(\mathrm{TOCs}-3 \mathrm{H}^{+}\right)\right]^{-}$. 

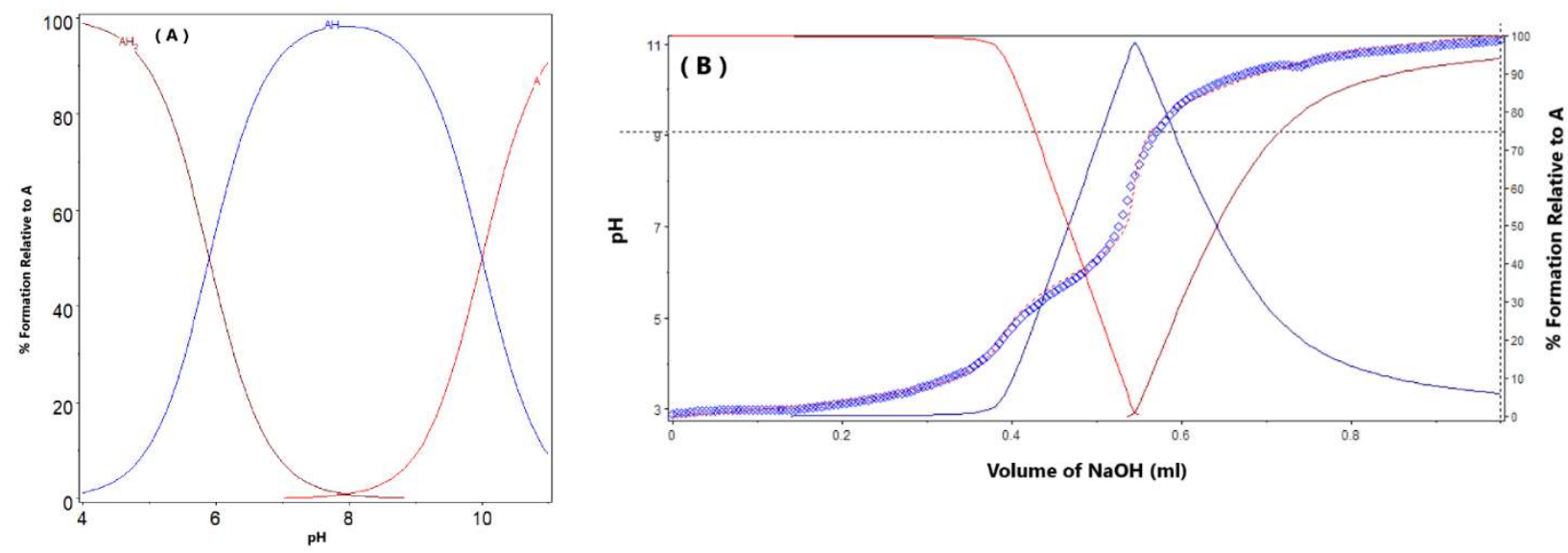

Figure S3. Speciation diagram (A) derived from potentiometric data (B) to represent a solution containing $1 \mathrm{mM} \mathrm{Co}$ (TOCO121) in $0.1 \mathrm{M} \mathrm{NaCl}$ at $25^{\circ} \mathrm{C}$. A represents the deprotonated complex $\left[\mathrm{Co}\left(\mathrm{TOCO}-2 \mathrm{H}^{+}\right)\right]$.

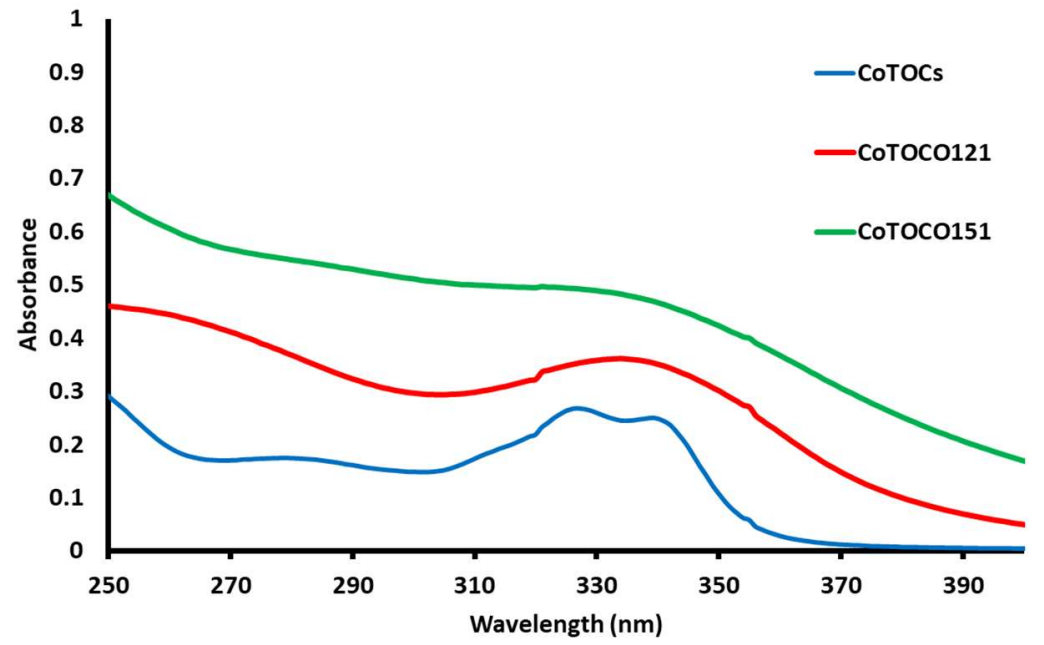

Figure S4. UV-Vis absorption spectra of (i) $50 \mu \mathrm{M}$ Co(TOCs) (blue) (ii) $50 \mu \mathrm{M}$ Co(TOCO121) (red) (iii) $50 \mu \mathrm{M}$ Co(TOCO151) (green). The solutions were prepared in HEPES buffer ( $\mathrm{pH} 7.2$ ) and 0.1 $\mathrm{M} \mathrm{NaCl}$ at room temperature. 


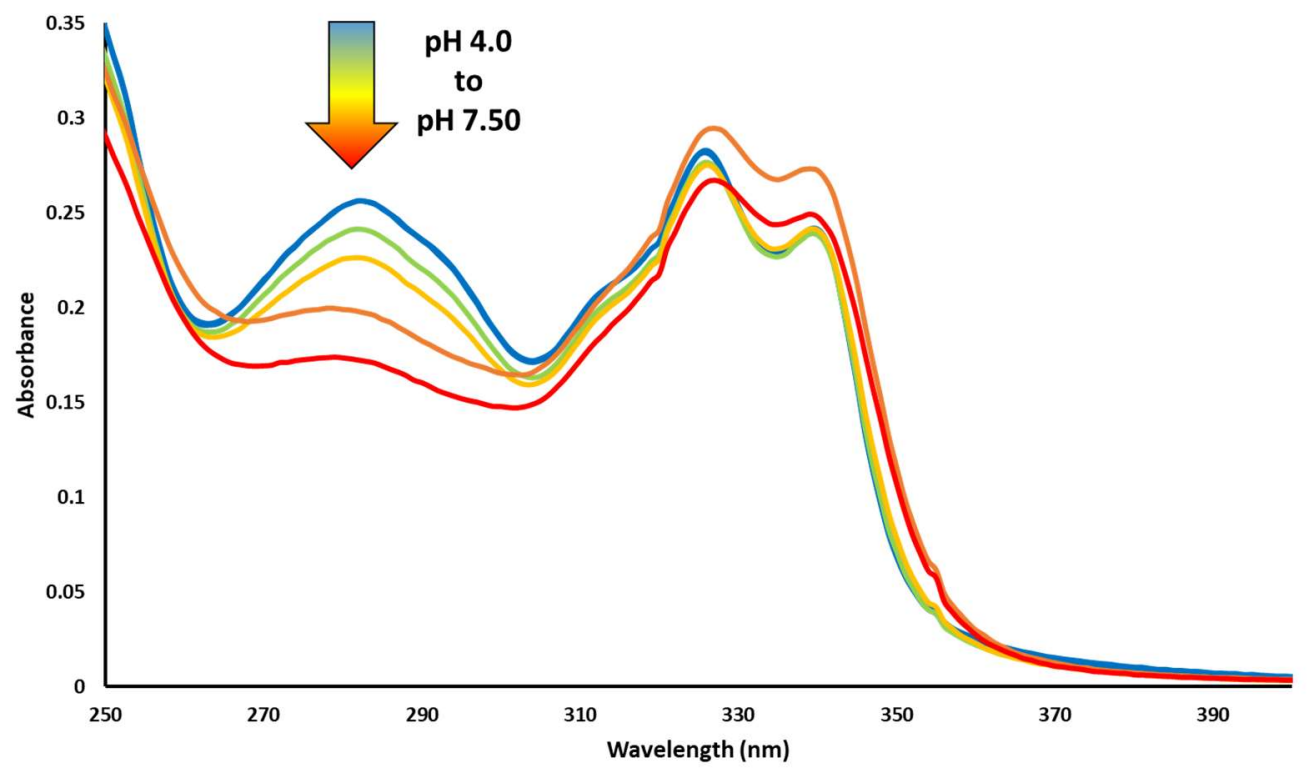

Figure S5. pH titrations of $10 \mu \mathrm{M}$ Co(TOCs) in UV-Vis spectra. Samples contain $20 \mathrm{mM} \mathrm{NaCl}$.

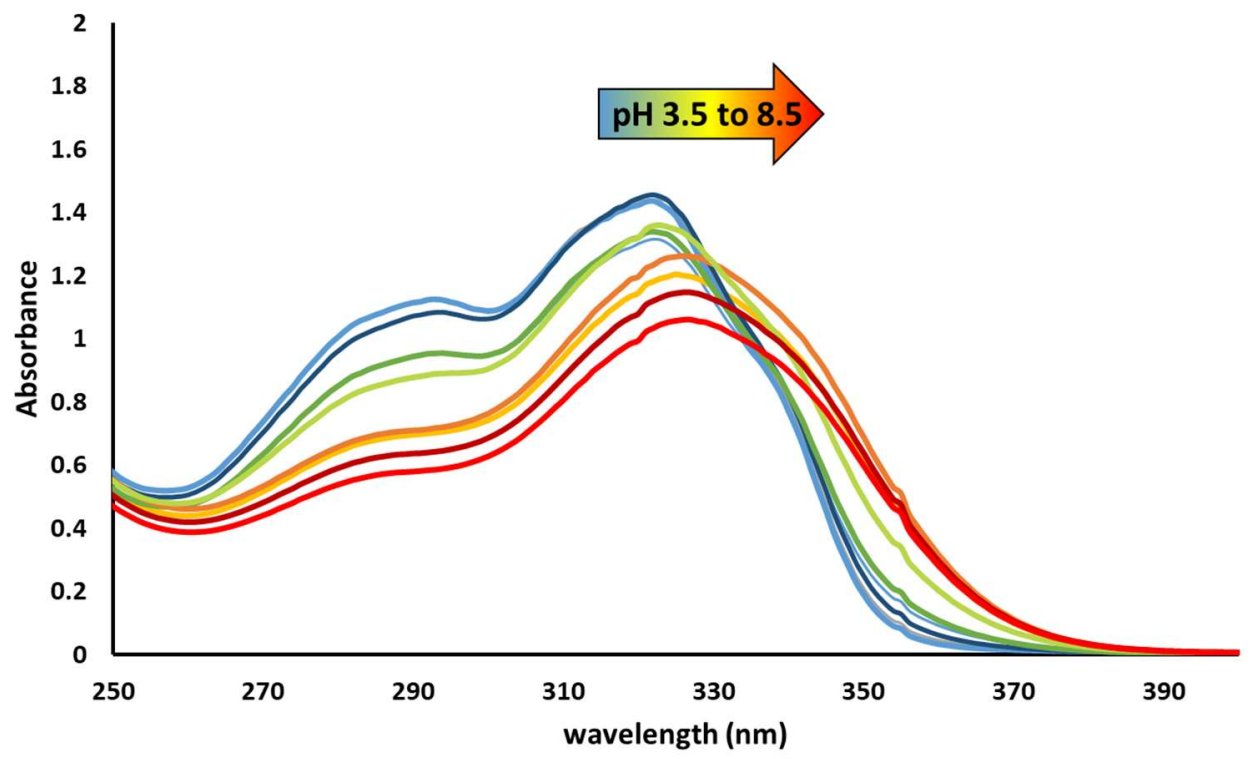

Figure S6. pH titrations of $100 \mu \mathrm{M}$ Co(TOCO121) in UV-Vis spectra. Samples contain $20 \mathrm{mM}$ $\mathrm{NaCl}$. 


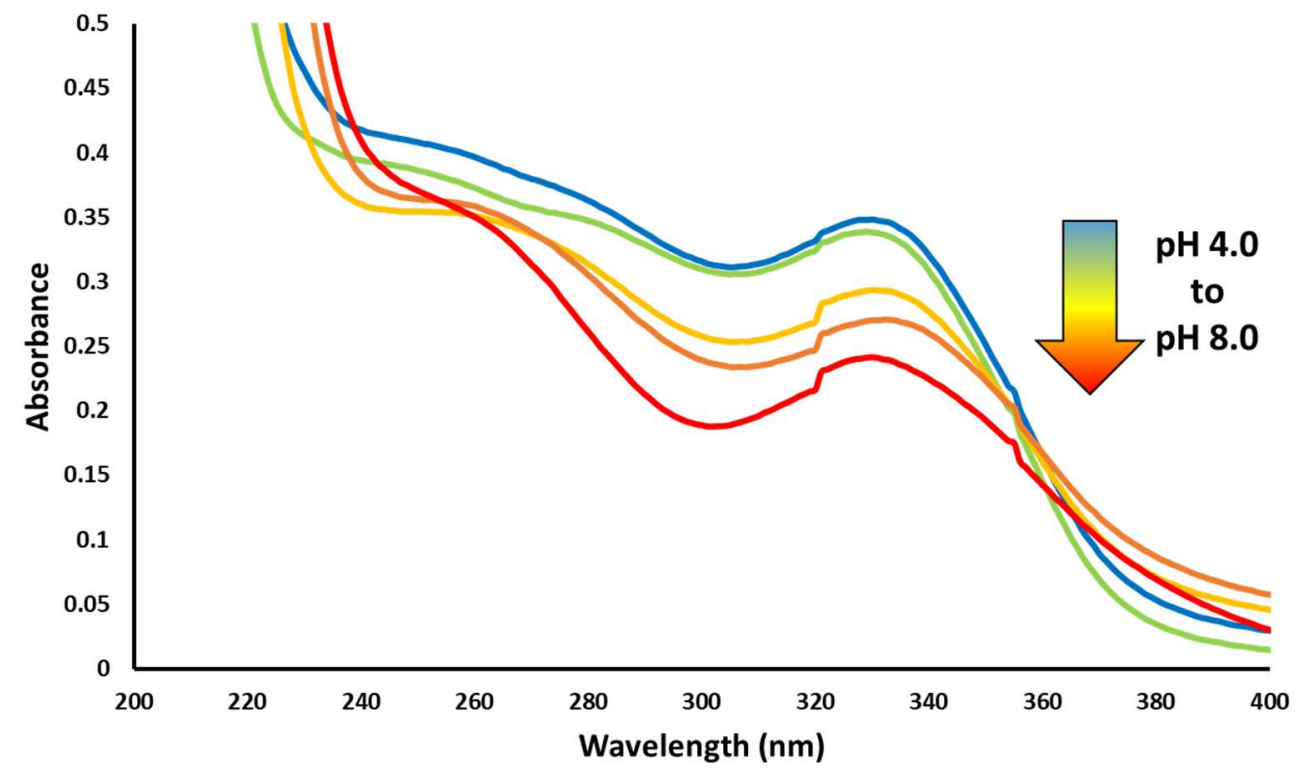

Figure S7. pH titrations of $50 \mu \mathrm{M}$ Co(TOCO151) UV-Vis spectra. Samples contain $20 \mathrm{mM} \mathrm{NaCl}$.

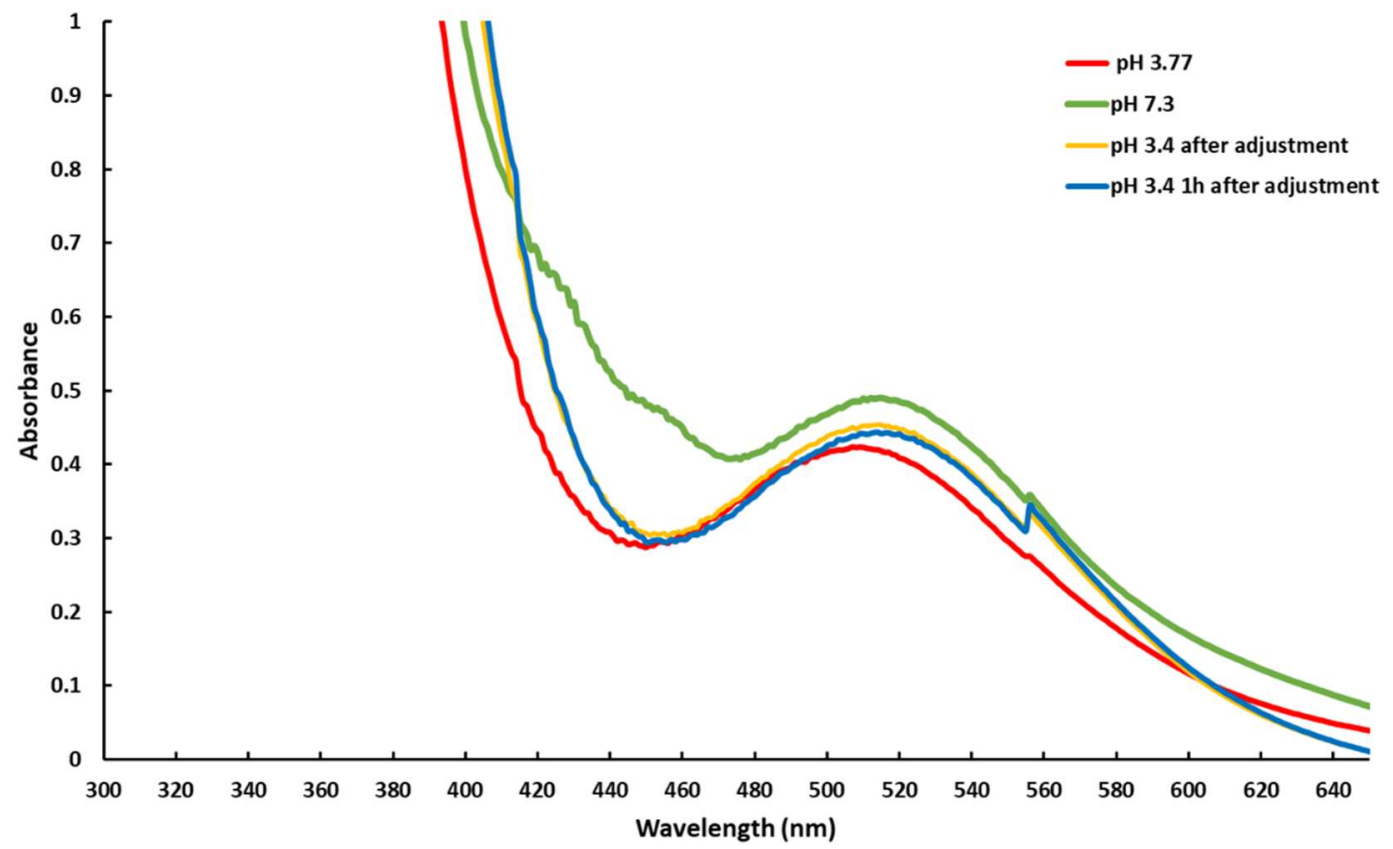

Figure S8. Electronic Spectra of $5.5 \mathrm{mM} \mathrm{Co(TOCO121)} \mathrm{in} \mathrm{H}_{2} \mathrm{O}$ at (a) $\mathrm{pH} 3.77$ (b) pH 7.3 (c) pH 3.4 after adjustment from $\mathrm{pH} 7.3$ and (d) $\mathrm{pH} 3.4,1 \mathrm{~h}$ after adjustment 


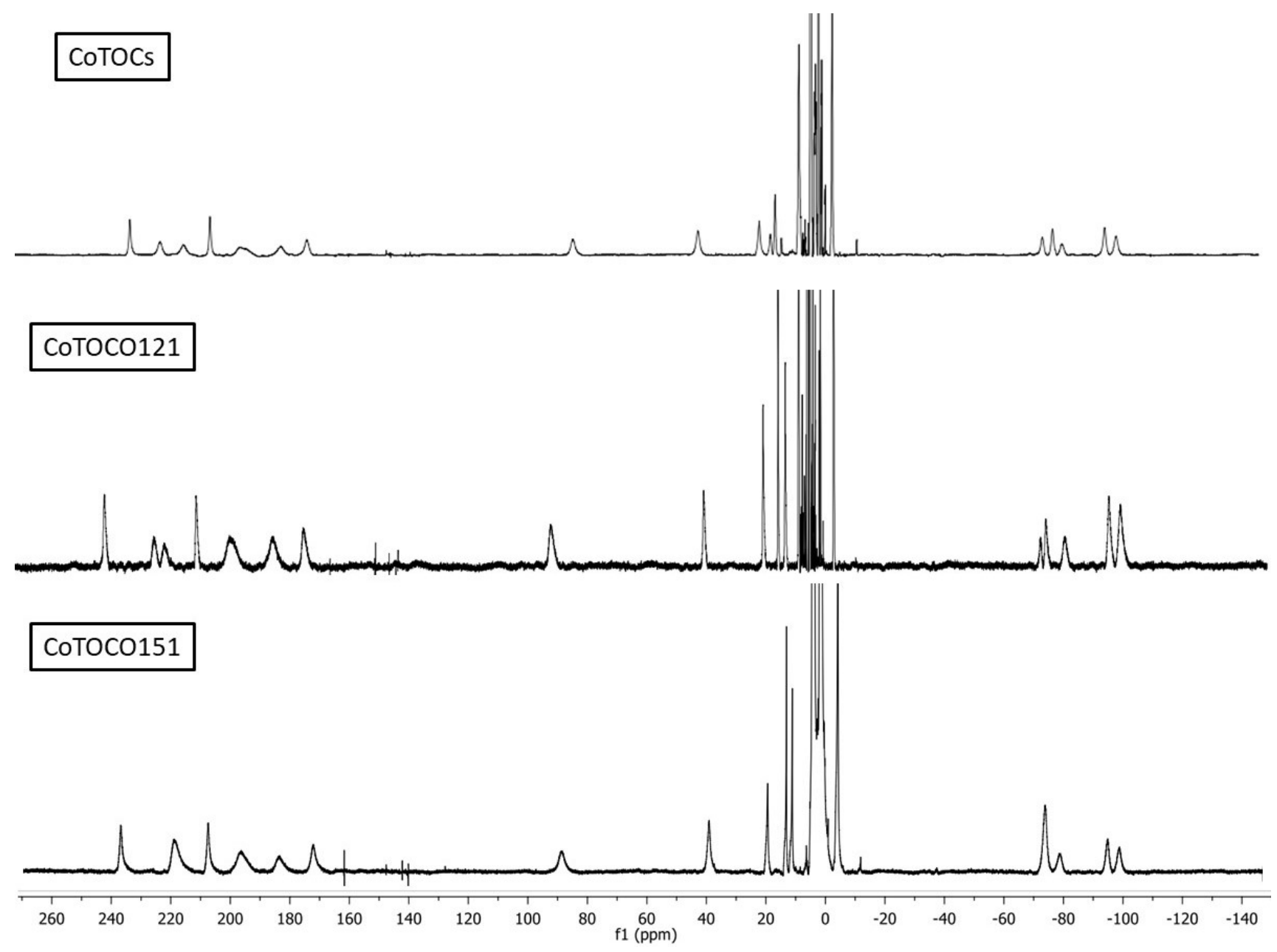

Figure S9. ${ }^{1} \mathrm{H}$ NMR spectrum of $\mathrm{Co}(\mathrm{II})$ complexes in $\mathrm{D}_{2} \mathrm{O}$ at $\mathrm{pH} 4.1,25{ }^{\circ} \mathrm{C}$ 


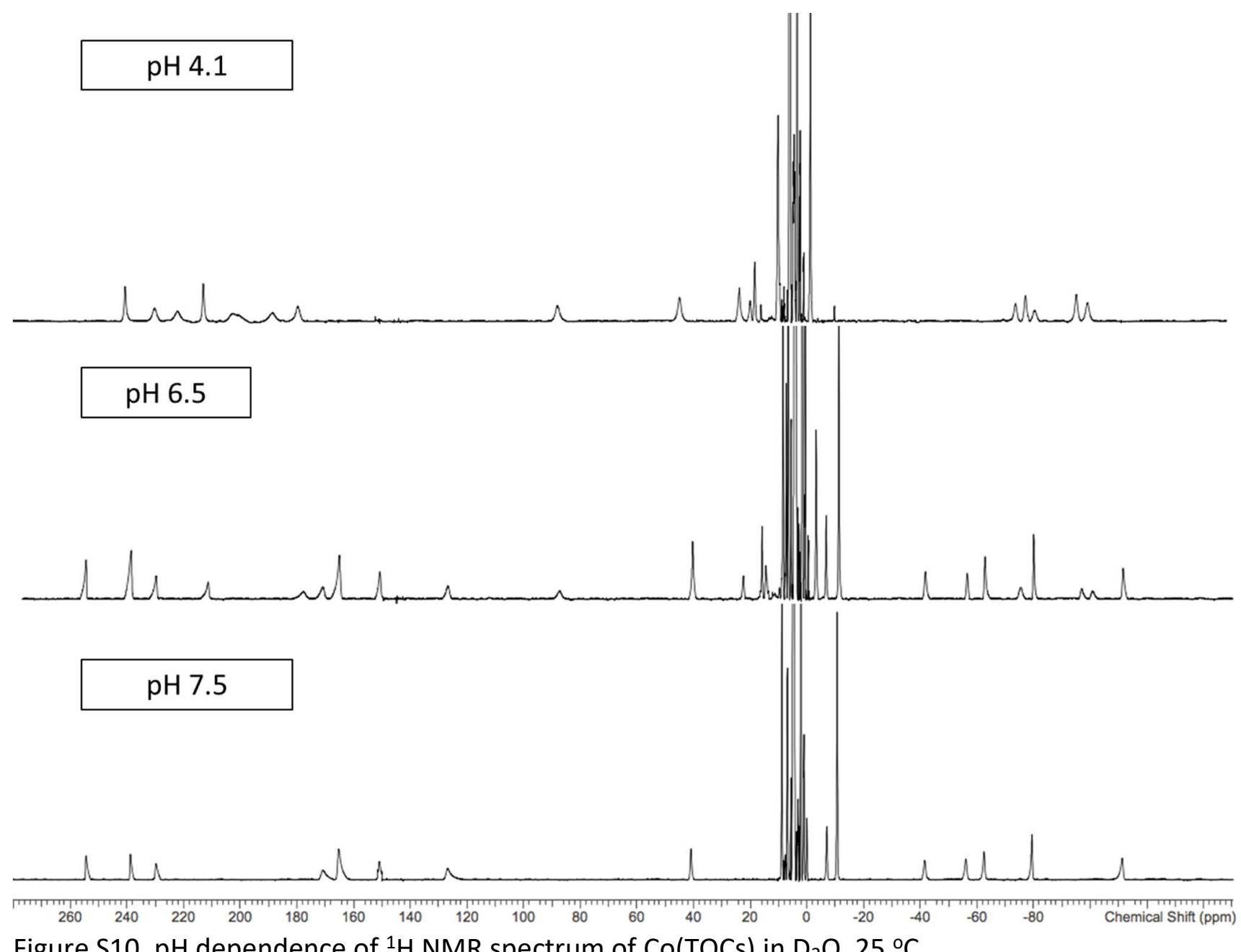

Figure S10. pH dependence of ${ }^{1} \mathrm{H}$ NMR spectrum of Co(TOCs) in $\mathrm{D}_{2} \mathrm{O}, 25^{\circ} \mathrm{C}$. 


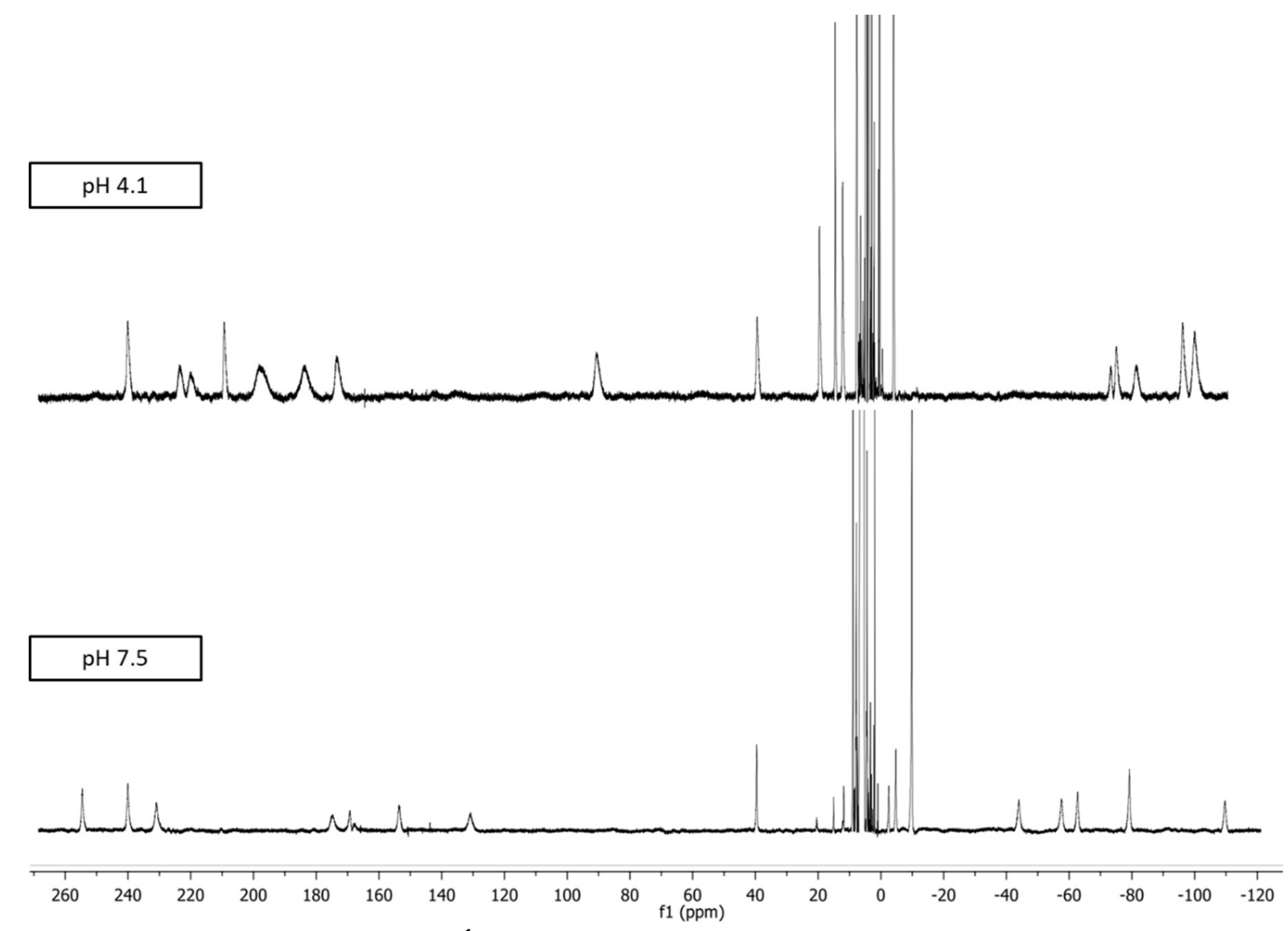

Figure S11. pH dependence of ${ }^{1} \mathrm{H}$ NMR spectrum of Co(TOCO121) in $\mathrm{D}_{2} \mathrm{O}, 25^{\circ} \mathrm{C}$. 


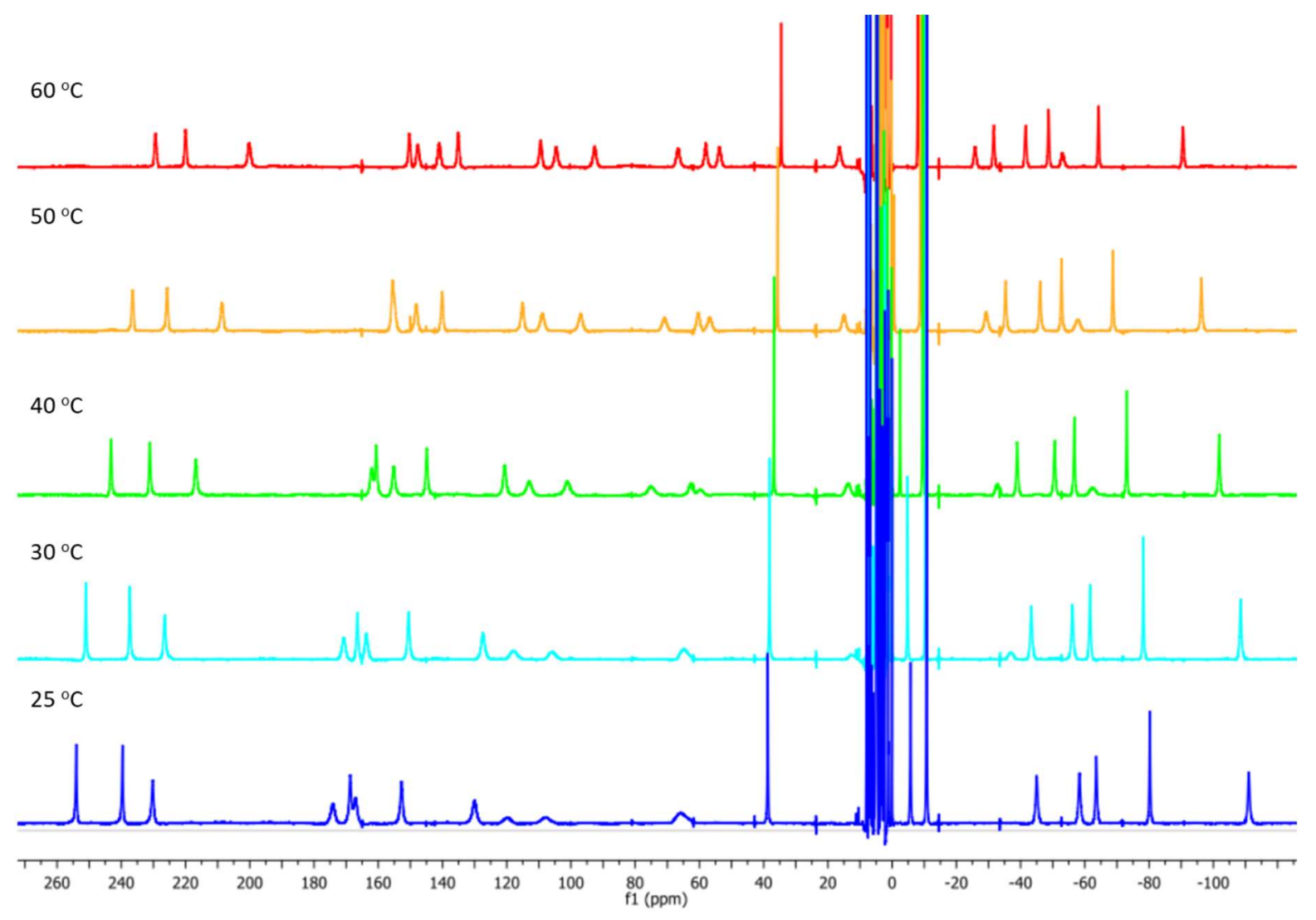

Figure S12. ${ }^{1} \mathrm{H}$ NMR of Co(TOCO121) in $\mathrm{D}_{2} \mathrm{O}$ at $60,50,40,30$ and $25^{\circ} \mathrm{C}$ (top to bottom). Resonances become more defined as temperature increases. Studies were done on a $400 \mathrm{MHz}$ NMR spectrometer. 


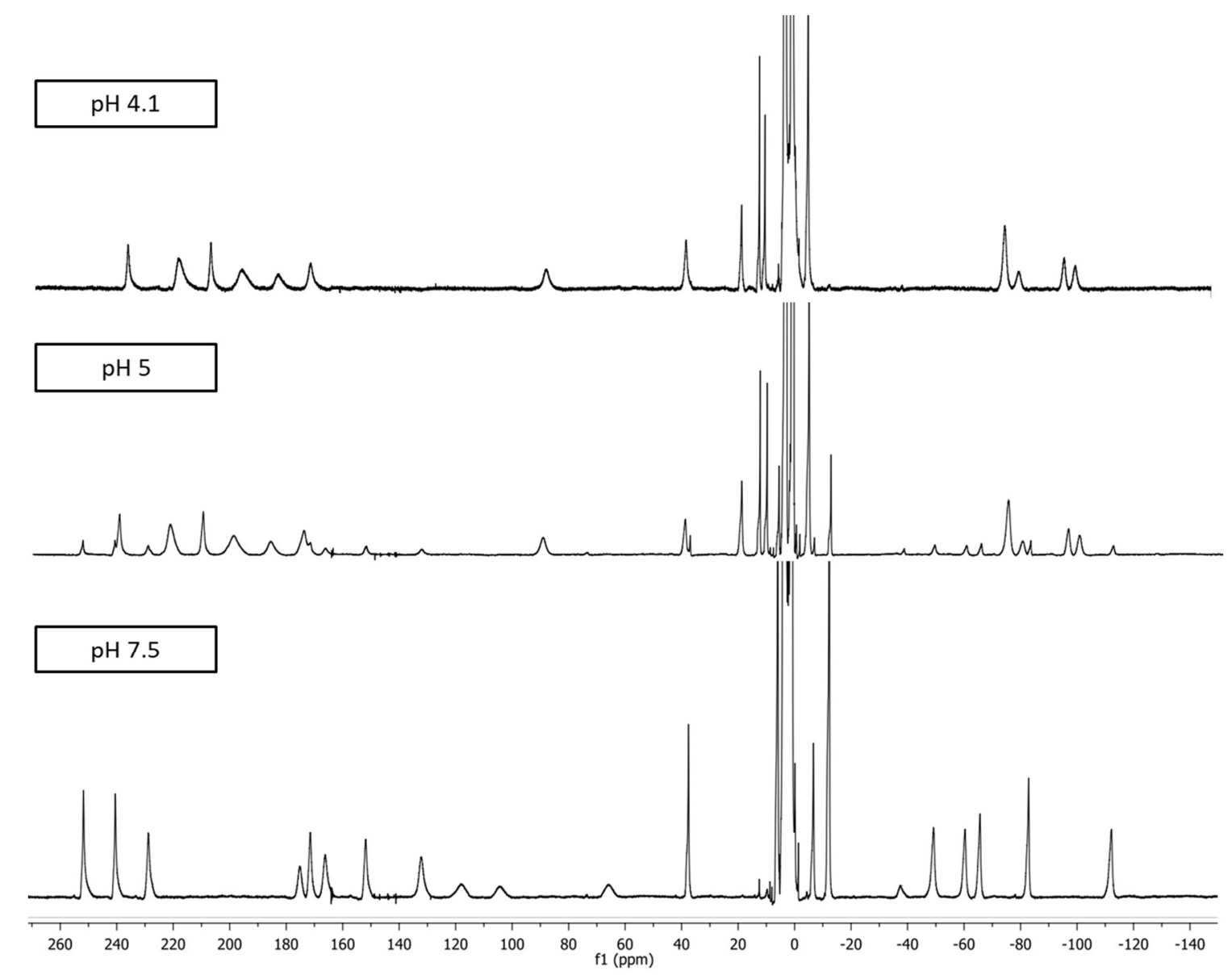

Figure S13. $\mathrm{pH}$ dependence of ${ }^{1} \mathrm{H}$ NMR spectrum of Co(TOCO151) in $\mathrm{D}_{2} \mathrm{O}, 25^{\circ} \mathrm{C}$. 


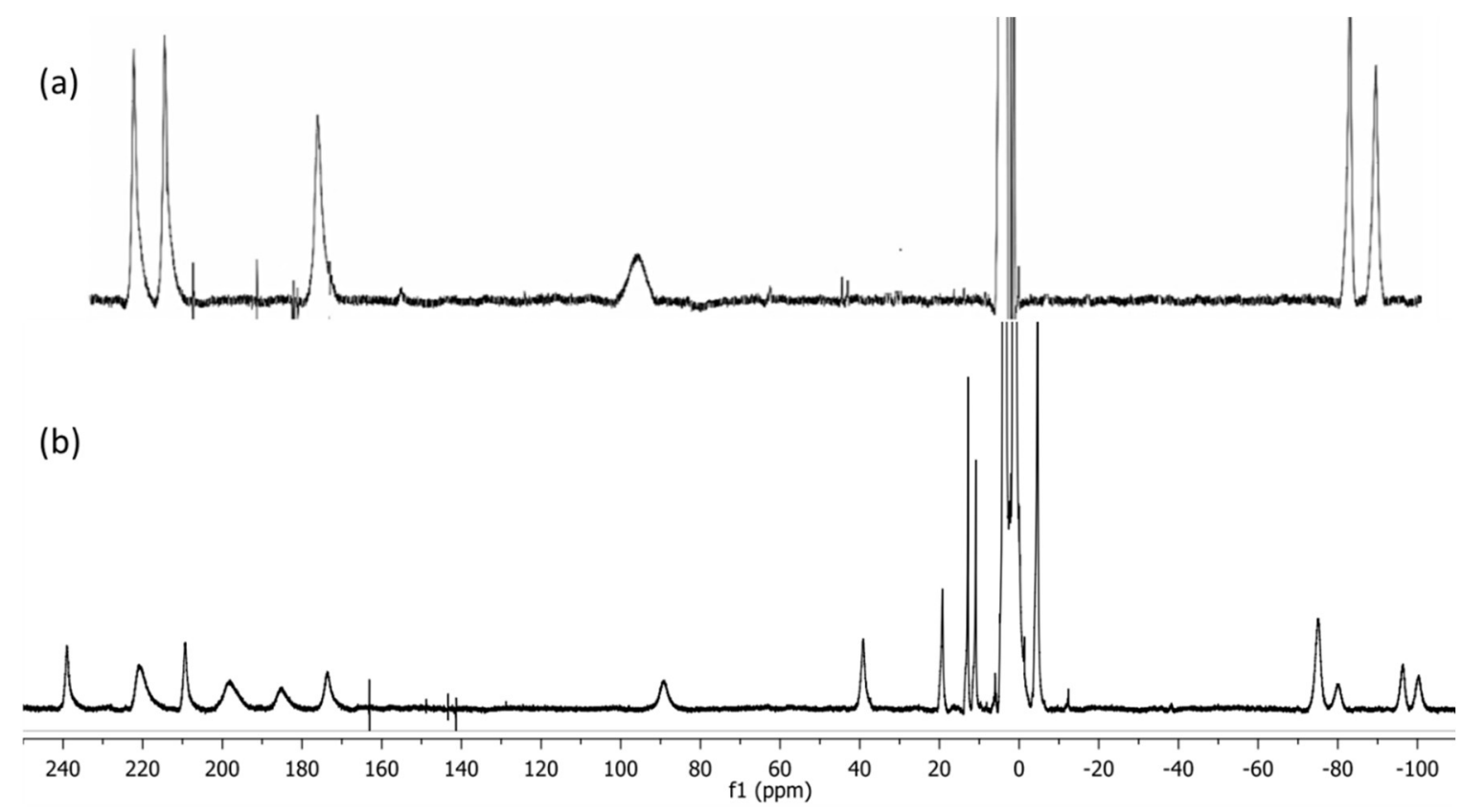

Figure S1. ${ }^{1} \mathrm{H}$ NMR of (a) [Co(TOT) at pH 6.6 and (b) Co(TOCO151) at pH 4.1 in $\mathrm{D}_{2} \mathrm{O}$.

(a)

(b)

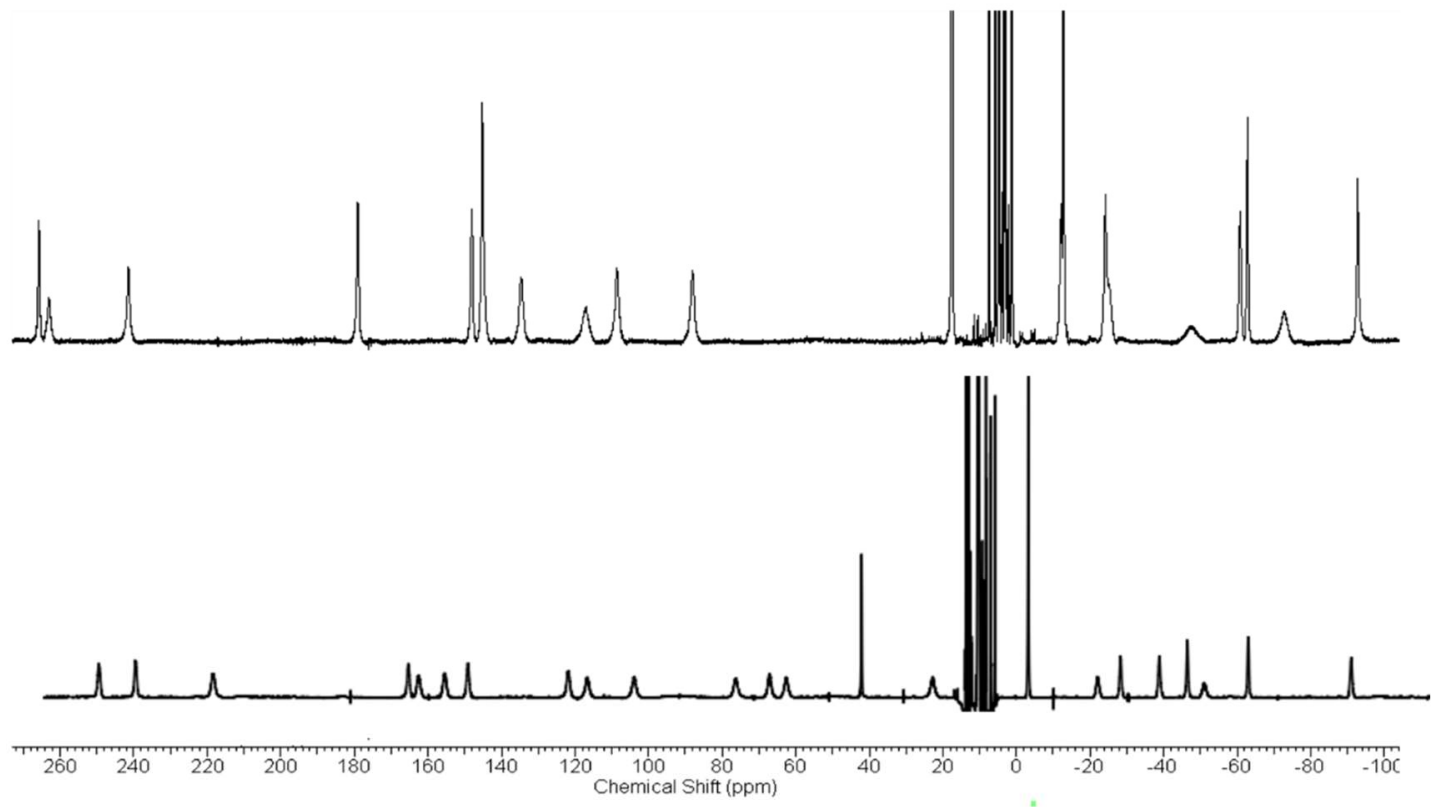

Figure S2. ${ }^{1} \mathrm{H}$ NMR of (a) Co(TOB) at pH 5.8 at $25^{\circ} \mathrm{C}$ and (b) Co(TOCO121) at pH 7.5 at $60{ }^{\circ} \mathrm{C}$ in $\mathrm{D}_{2} \mathrm{O}$. 

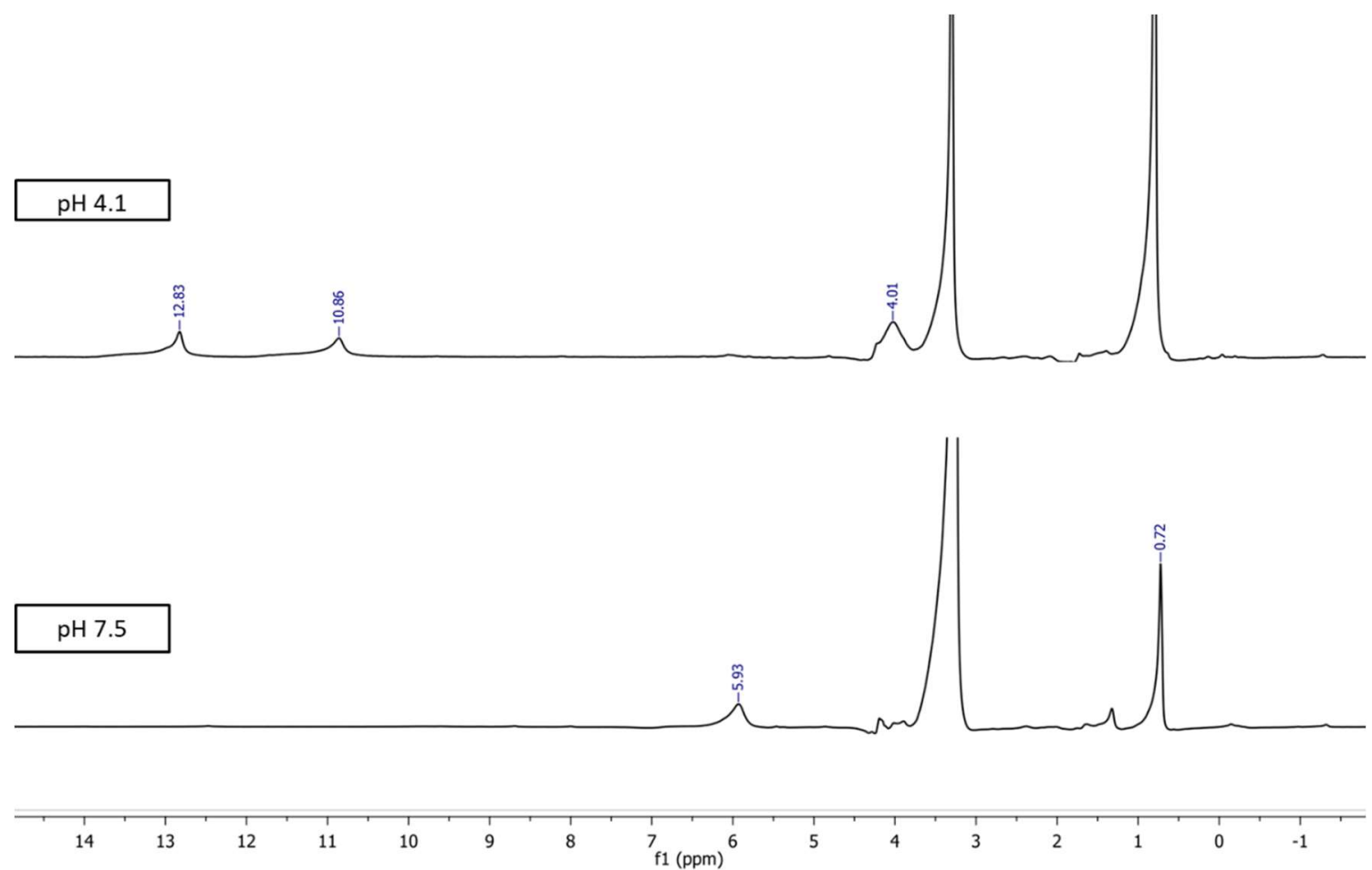

Figure S3. $\mathrm{pH}$ dependence of ${ }^{1} \mathrm{H}$ NMR spectrum in diamagnetic region of $\mathrm{Co}(\mathrm{TOCO} 151)$ in $\mathrm{D}_{2} \mathrm{O}$, $25^{\circ} \mathrm{C}$.

(a)

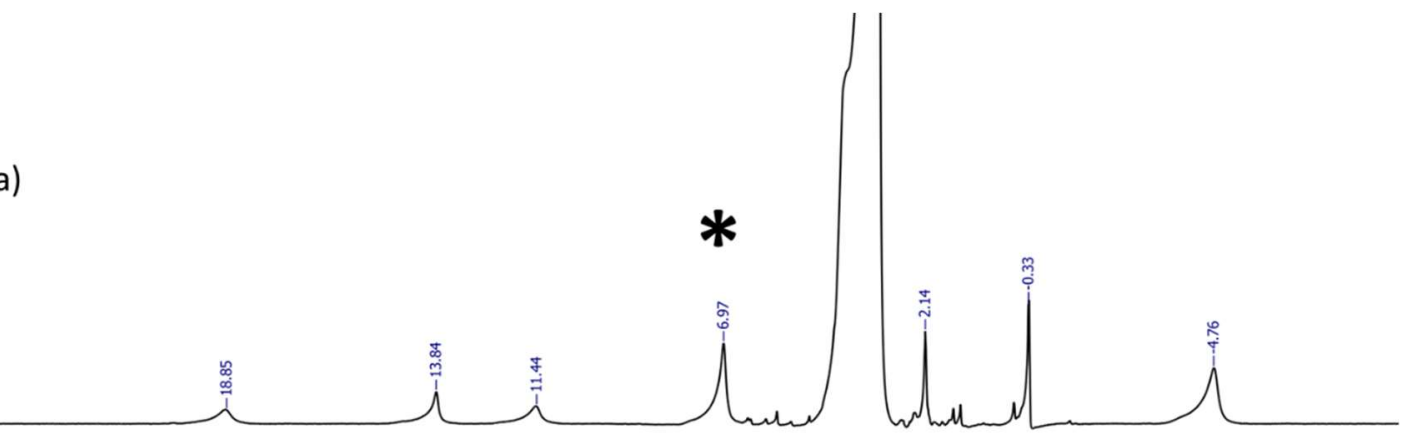

(b)
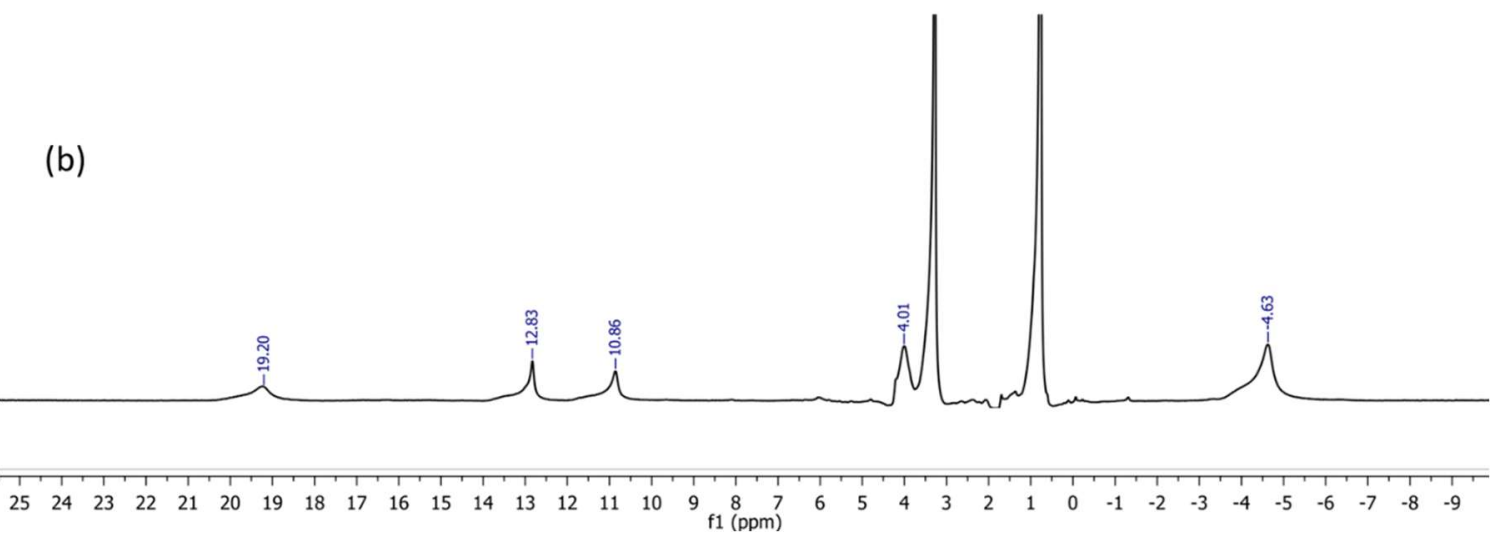

Figure S4. ${ }^{1} \mathrm{H}$ NMR spectrum in diamagnetic region of (a) Co(TOCO121) and (b) Co(TOCO151) at $\mathrm{pH} 4.1$ in $\mathrm{D}_{2} \mathrm{O}, 25^{\circ} \mathrm{C}$. 


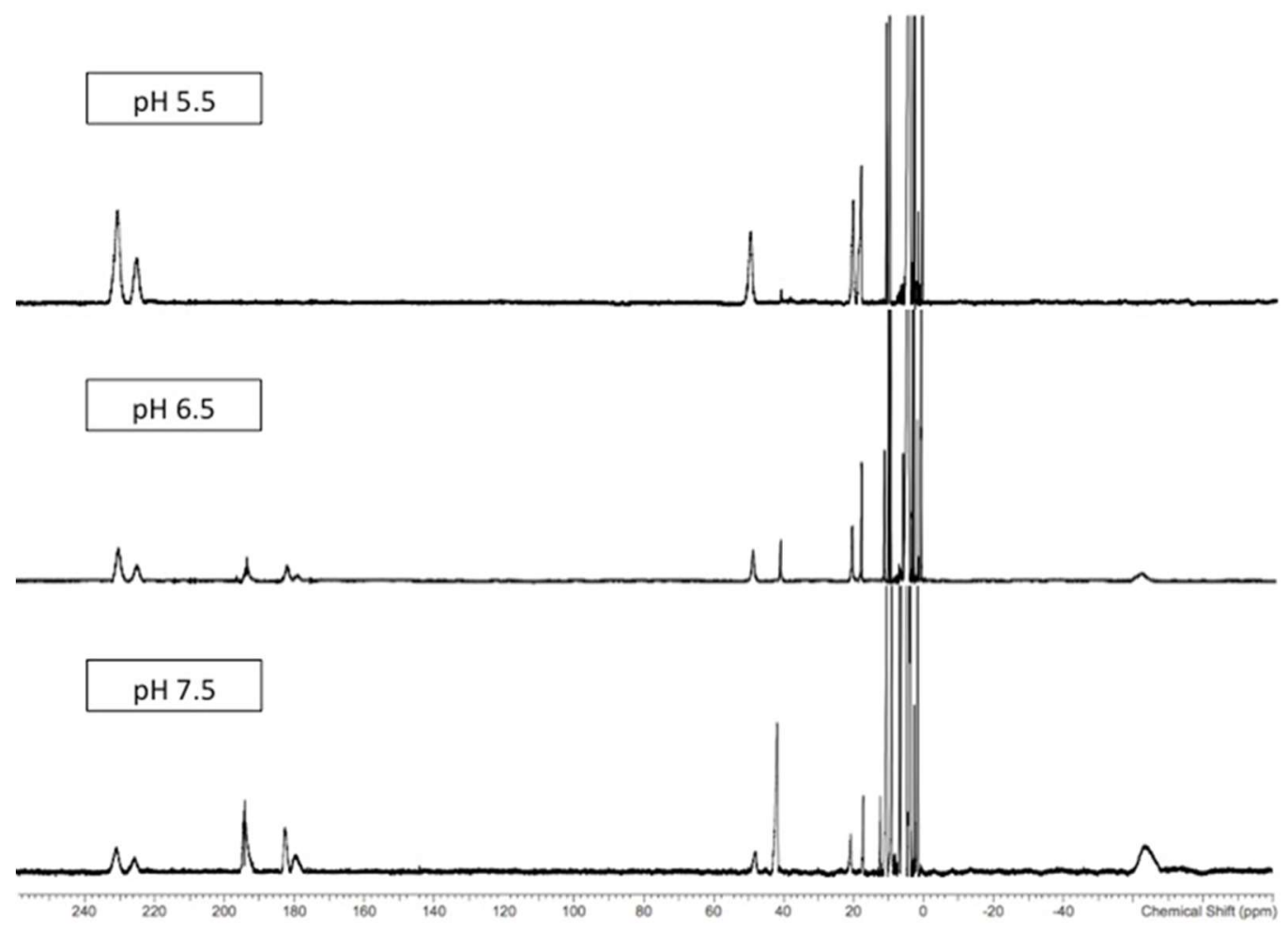

Figure S5. ${ }^{1} \mathrm{H}$ NMR spectra at three $\mathrm{pH}$ values of $\mathrm{Co}(\mathrm{TACs})$ in $\mathrm{D}_{2} \mathrm{O}, 25^{\circ} \mathrm{C}$.

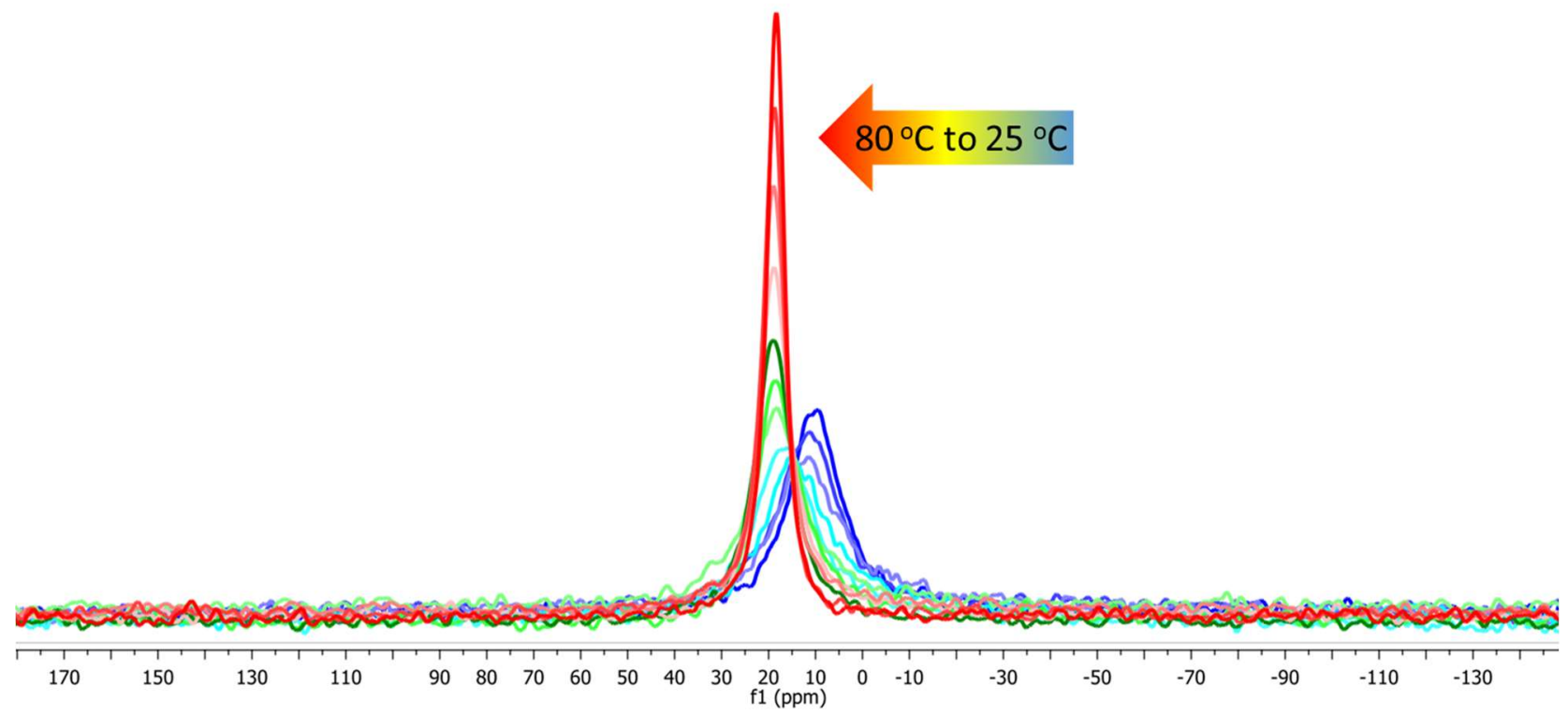

Figure S6. Variable temperature ${ }^{17} \mathrm{O}$ NMR spectra of a $40 \mathrm{mM} \mathrm{Co}$ (TOCs) sample in $1 \% \mathrm{H}_{2}{ }^{17} \mathrm{O}$ in $20 \mathrm{mM} \mathrm{pH} 6$ HEPES and $100 \mathrm{mM} \mathrm{NaCl}$, from 25 to $80^{\circ} \mathrm{C}$. 


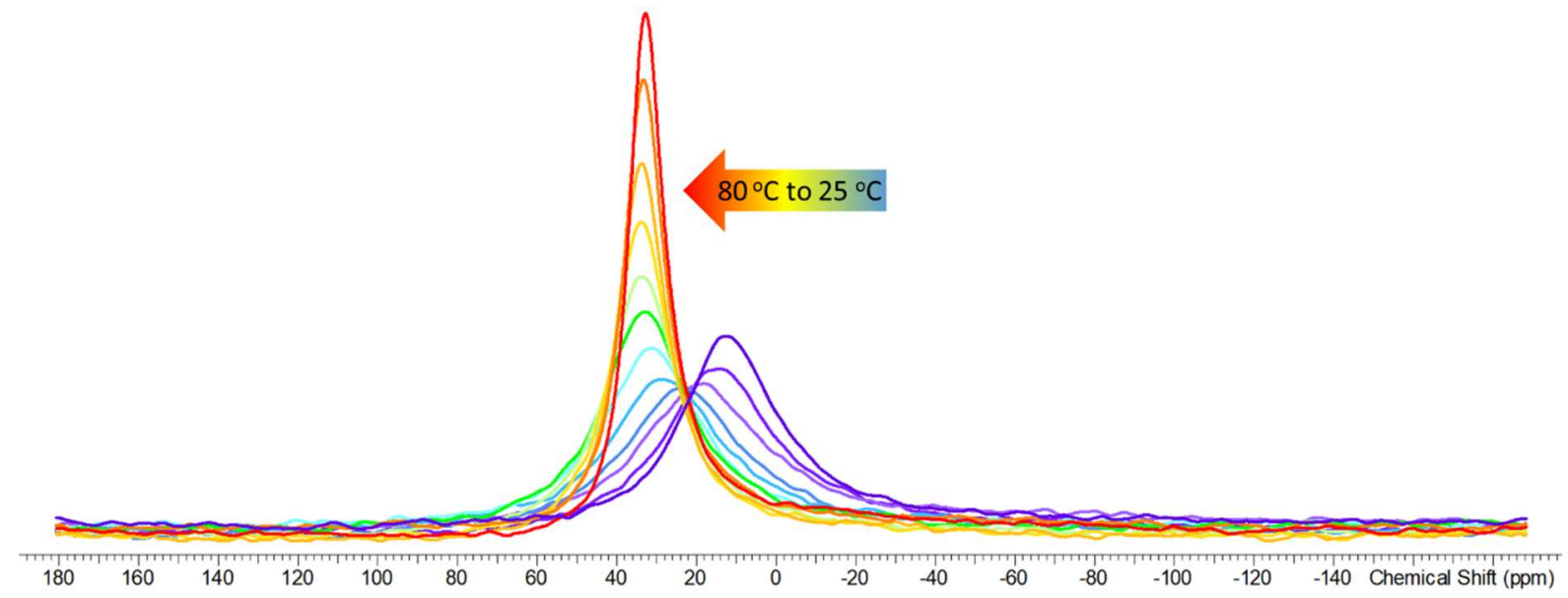

Figure S7. Variable temperature ${ }^{17} \mathrm{O}$ NMR spectra of a $40 \mathrm{mM} \mathrm{Co}(\mathrm{TOCO} 121)$ sample in $1 \% \mathrm{H}_{2}{ }^{17} \mathrm{O}$ in $20 \mathrm{mM} \mathrm{pH} 7 \mathrm{HEPES}$ and $100 \mathrm{mM} \mathrm{NaCl}$, from 25 to $80^{\circ} \mathrm{C}$.

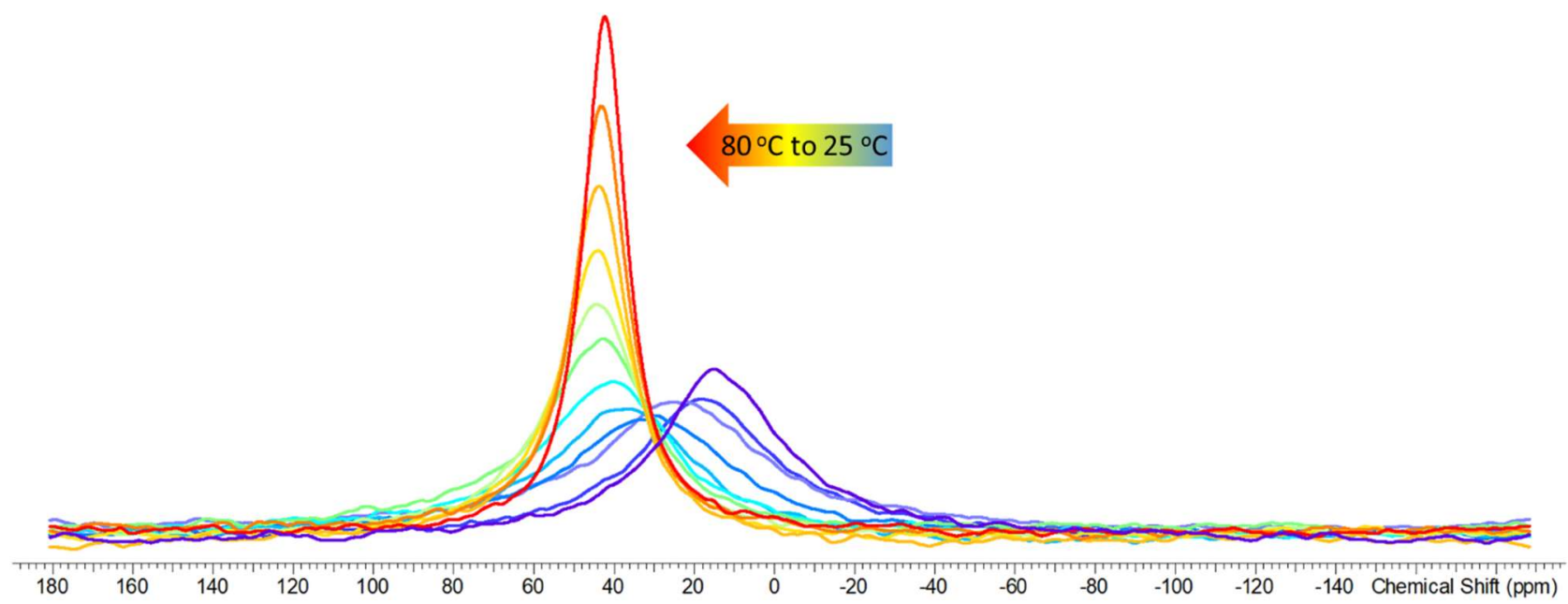

Figure S8. Variable temperature ${ }^{17} \mathrm{O}$ NMR spectra of a $40 \mathrm{mM} \mathrm{Co}$ (TOCO151) sample in $1 \% \mathrm{H}_{2}{ }^{17} \mathrm{O}$ in $20 \mathrm{mM} \mathrm{pH} 7 \mathrm{HEPES}$ and $100 \mathrm{mM} \mathrm{NaCl}$, from 25 to $80^{\circ} \mathrm{C}$. 


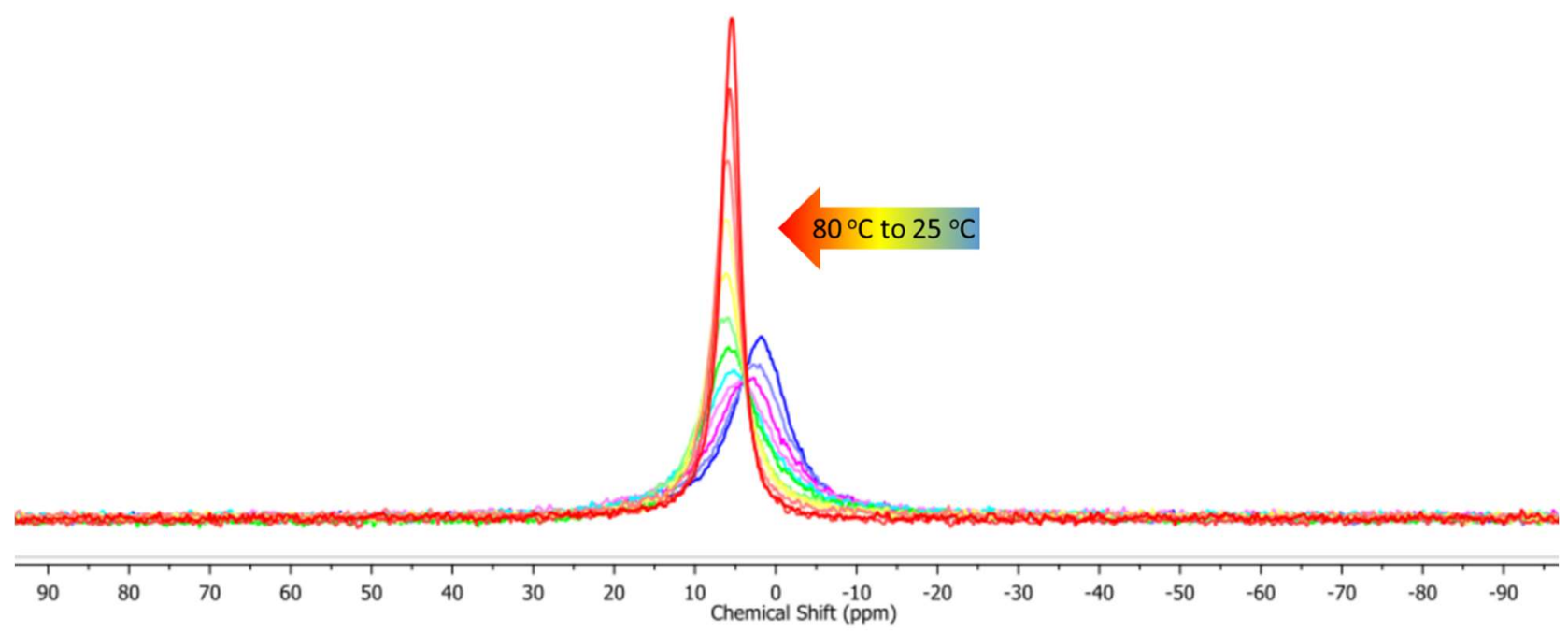

Figure S9. Variable temperature ${ }^{17} \mathrm{O}$ NMR spectra of a $40 \mathrm{mM}$ Co(TACs) sample in $1 \% \mathrm{H}_{2}{ }^{17} \mathrm{O}$ in $20 \mathrm{mM} \mathrm{pH} 6 \mathrm{HEPES}$ and $100 \mathrm{mM} \mathrm{NaCl}$, from 25 to $80^{\circ} \mathrm{C}$.

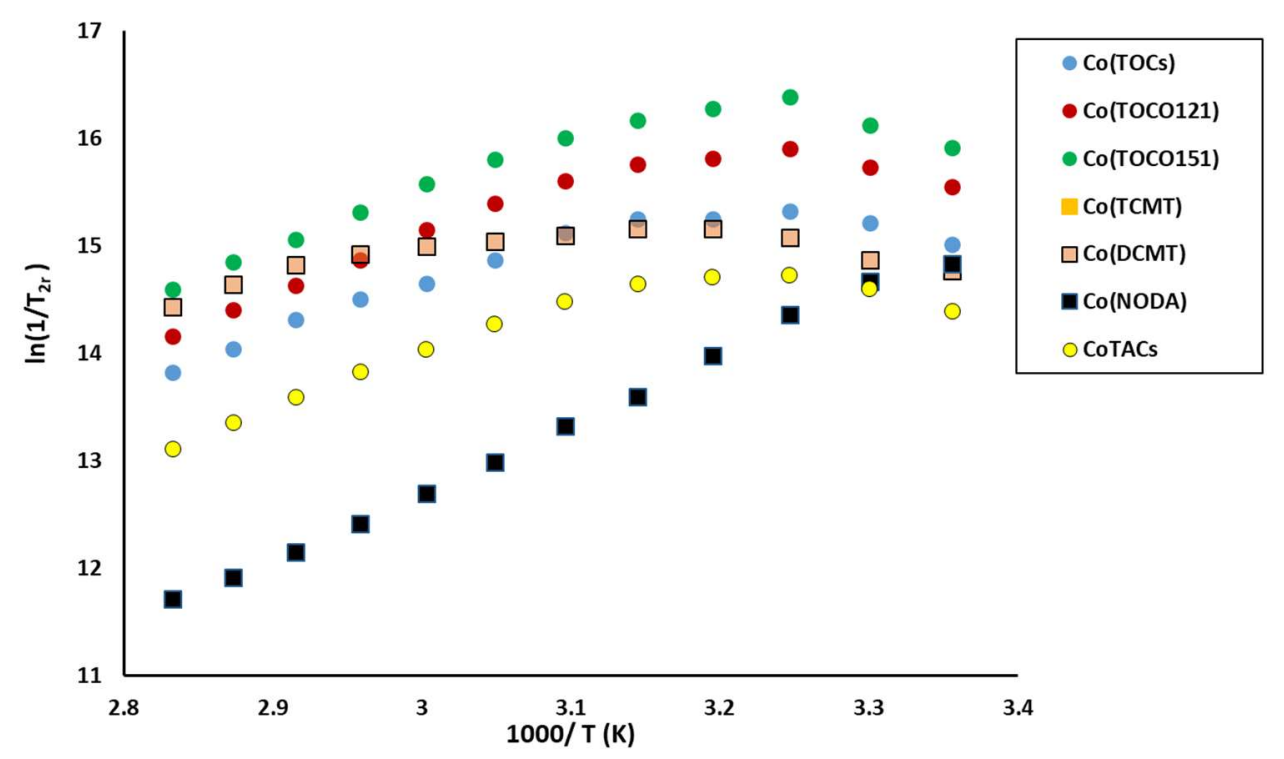

Figure S10. Comparison of $40 \mathrm{mM}$ Co(TOCs), $40 \mathrm{mM}$ Co(TOCO121), $40 \mathrm{mM}$ Co(TOCO151), 30 $\mathrm{mM}$ Co(TACs), $50 \mathrm{mM} \mathrm{Co}(\mathrm{NODA})\left(\mathrm{H}_{2} \mathrm{O}\right) 100 \mathrm{mM} \mathrm{Co}(\mathrm{DCMT})$ and $100 \mathrm{mM} \mathrm{Co}(\mathrm{TCMT}){ }^{17} \mathrm{O} \mathrm{NMR}$ resonance broadening at $\mathrm{pH} 6.0$ as a function of temperature. See Scheme S3 for complexes. 


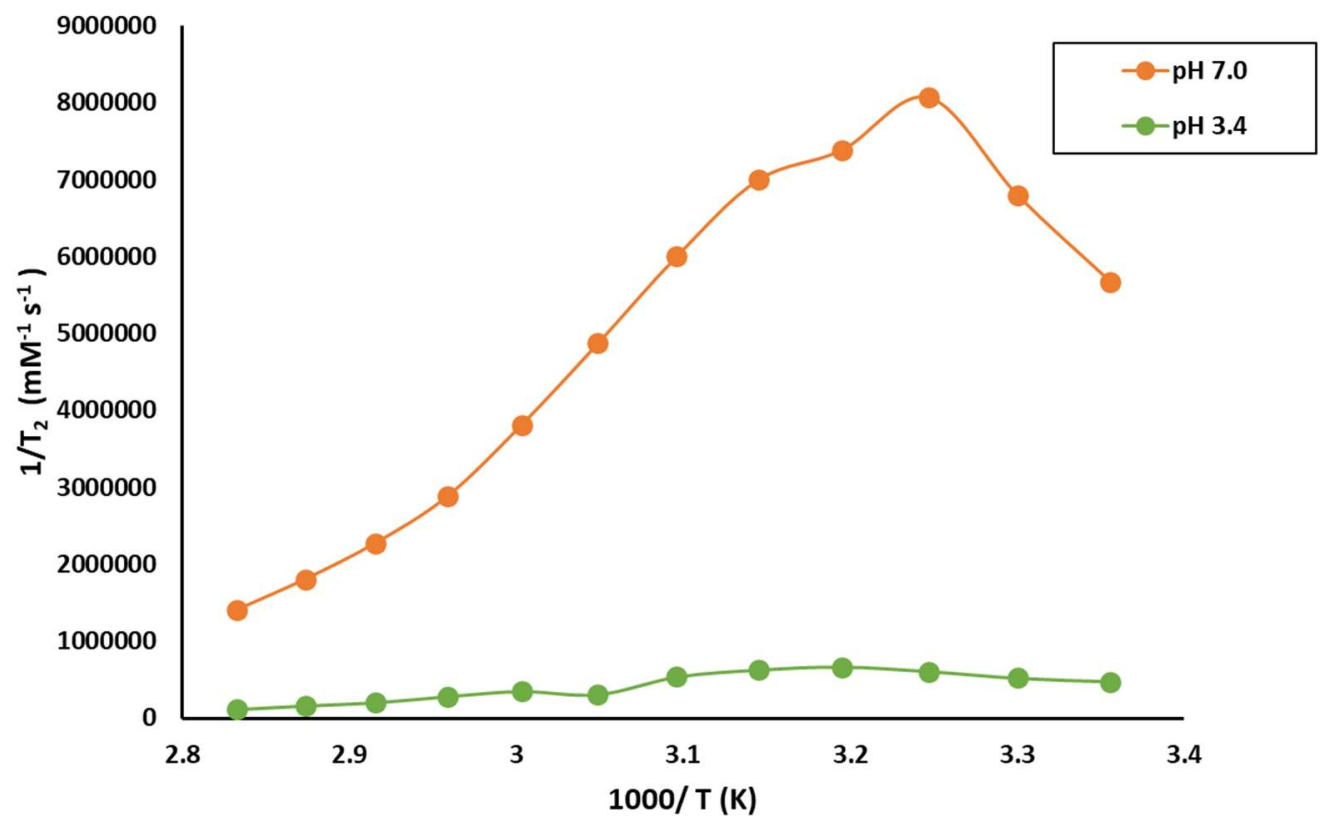

Figure S11. Comparison of ${ }^{17} \mathrm{O}$ NMR resonance broadening as a function of temperature for 40 $\mathrm{mM} \mathrm{Co}(\mathrm{TOCO} 121)$ at (a) $\mathrm{pH} 7.0$ and (b) pH 3.4.

Table S4. Calculated transverse relaxation rate and reduced chemical shift of Co(TOCs) from variable temperature ${ }^{17} \mathrm{O}$ NMR experiments.

\begin{tabular}{|c|c|c|c|}
\hline $1000 / T$ & $\begin{array}{l}1 / T_{2 r} \\
\left(\times 10^{6}\right)\end{array}$ & $\ln \left(1 / T_{2 r}\right)$ & $\begin{array}{l}\text { Reduced Chemical } \\
\text { shift }\left(10^{6} \mathrm{rad} \mathrm{s}^{-1}\right)\end{array}$ \\
\hline 3.356 & 3.33 & 15.0 & 0.709 \\
\hline 3.300 & 4.06 & 15.2 & 0.821 \\
\hline 3.247 & 4.53 & 15.3 & 1.034 \\
\hline 3.195 & 4.21 & 15.3 & 1.324 \\
\hline 3.145 & 4.22 & 15.3 & 1.490 \\
\hline 3.096 & 3.70 & 15.1 & 1.654 \\
\hline 3.049 & 2.87 & 14.9 & 1.748 \\
\hline 3.003 & 2.31 & 14.7 & 1.771 \\
\hline 2.959 & 1.99 & 14.5 & 1.809 \\
\hline 2.915 & 1.66 & 14.3 & 1.820 \\
\hline 2.874 & 1.26 & 14.0 & 1.874 \\
\hline 2.833 & 1.01 & 13.8 & 1.862 \\
\hline
\end{tabular}


Table S5. Calculated transverse relaxation rate and reduced chemical shift of Co(TOCO121) from variable temperature ${ }^{17} \mathrm{O}$ NMR experiments.

\begin{tabular}{|c|c|c|c|}
\hline $\mathbf{1 0 0 0 / T}$ & $\mathbf{1 /} \mathbf{T}_{\mathbf{2 r}} \mathbf{( \times 1 \mathbf { 1 } ^ { \mathbf { 6 } } )}$ & $\operatorname{In}\left(\mathbf{1} / \mathbf{T}_{\mathbf{2 r}}\right)$ & $\begin{array}{c}\text { Reduced Chemical shift } \\
\left(\mathbf{1 0 ^ { 6 }} \mathbf{r a d ~ s}^{\mathbf{1}}\right)\end{array}$ \\
\hline 3.356 & 5.67 & 15.5 & 1.248 \\
\hline 3.300 & 6.80 & 15.7 & 1.765 \\
\hline 3.247 & 8.08 & 15.9 & 2.152 \\
\hline 3.195 & 7.39 & 15.8 & 3.037 \\
\hline 3.145 & 7.00 & 15.8 & 3.972 \\
\hline 3.096 & 6.01 & 15.6 & 4.126 \\
\hline 3.049 & 4.87 & 15.4 & 4.418 \\
\hline 3.003 & 3.81 & 15.2 & 4.753 \\
\hline 2.959 & 2.88 & 14.9 & 4.706 \\
\hline 2.915 & 2.27 & 14.6 & 4.716 \\
\hline 2.874 & 1.81 & 14.4 & 4.668 \\
\hline 2.833 & 1.41 & 14.2 & 4.695 \\
\hline
\end{tabular}

Table S6. Calculated transverse relaxation rate and reduced chemical shift of Co(TOCO151) from variable temperature ${ }^{17} \mathrm{O}$ NMR experiments.

\begin{tabular}{|c|c|c|c|}
\hline $1000 / T$ & $1 / \mathrm{T}_{2 \mathrm{r}}\left(\times 10^{6}\right)$ & $\ln \left(1 / T_{2 r}\right)$ & $\begin{array}{l}\text { Reduced Chemical } \\
\text { shift }\left(10^{6} \mathrm{rad} \mathrm{s}^{-1}\right)\end{array}$ \\
\hline 3.356 & 8.20 & 15.9 & 1.348 \\
\hline 3.300 & 10.13 & 16.1 & 1.829 \\
\hline 3.247 & 13.16 & 16.4 & 2.270 \\
\hline 3.195 & 11.81 & 16.3 & 3.347 \\
\hline 3.145 & 10.54 & 16.2 & 4.269 \\
\hline 3.096 & 8.97 & 16.0 & 4.817 \\
\hline 3.049 & 7.34 & 15.8 & 5.200 \\
\hline 3.003 & 5.84 & 15.6 & 5.422 \\
\hline 2.959 & 4.49 & 15.3 & 5.447 \\
\hline 2.915 & 3.46 & 15.1 & 5.453 \\
\hline 2.874 & 2.81 & 14.8 & 5.404 \\
\hline 2.833 & 2.18 & 14.6 & 5.358 \\
\hline
\end{tabular}


Table S7. Calculated transverse relaxation rate and reduced chemical shift of Co(TACs) from variable temperature ${ }^{17} \mathrm{O}$ NMR experiments.

\begin{tabular}{|c|c|c|c|}
\hline $1000 / \mathrm{T}$ & $1 / T_{2 r}\left(\times 10^{6}\right)$ & $\ln \left(1 / T_{2 r}\right)$ & $\begin{array}{c}\text { Reduced Chemical shift } \\
\left(10^{6} \mathrm{rad} \mathrm{s}^{-1}\right)\end{array}$ \\
\hline 3.356 & 1.78 & 14.4 & 0.745 \\
\hline 3.300 & 2.20 & 14.6 & 0.796 \\
\hline 3.247 & 2.49 & 14.7 & 0.847 \\
\hline 3.195 & 2.45 & 14.7 & 0.884 \\
\hline 3.145 & 2.29 & 14.6 & 0.904 \\
\hline 3.096 & 1.95 & 14.5 & 0.911 \\
\hline 3.049 & 1.58 & 14.3 & 0.904 \\
\hline 3.003 & 1.25 & 14.0 & 0.899 \\
\hline 2.959 & 1.01 & 13.8 & 0.887 \\
\hline 2.915 & 0.80 & 13.6 & 0.877 \\
\hline 2.874 & 0.63 & 13.4 & 0.865 \\
\hline 2.833 & 0.50 & 13.1 & 0.850 \\
\hline
\end{tabular}

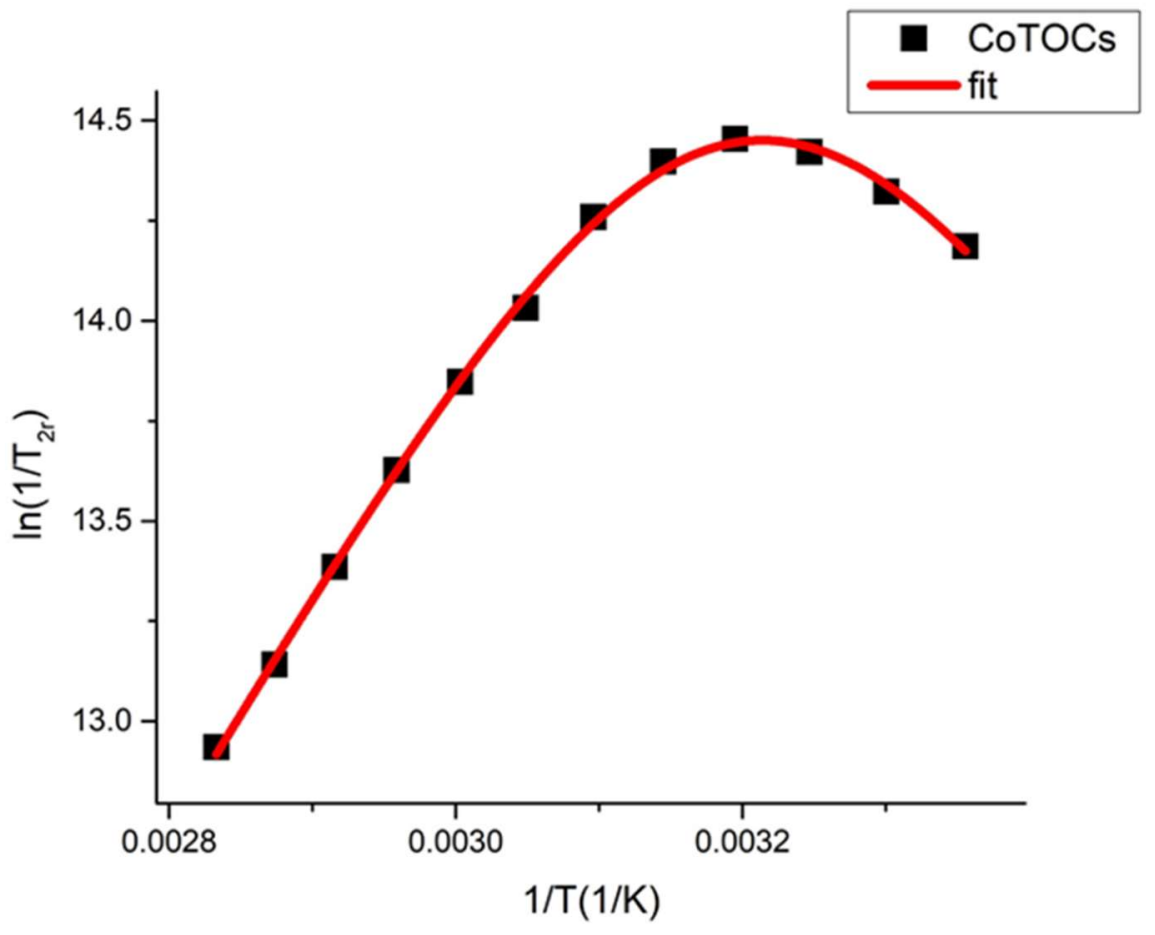

Figure S12. Transverse ${ }^{17} \mathrm{O}$ relaxivity, $\ln \left(1 / \mathrm{T}_{2 r}\right)$ as a function of temperature at $9.4 \mathrm{~T}$ for Co(TOCs) in water at $\mathrm{pH} 6$. Solid lines represent fit of the data. 


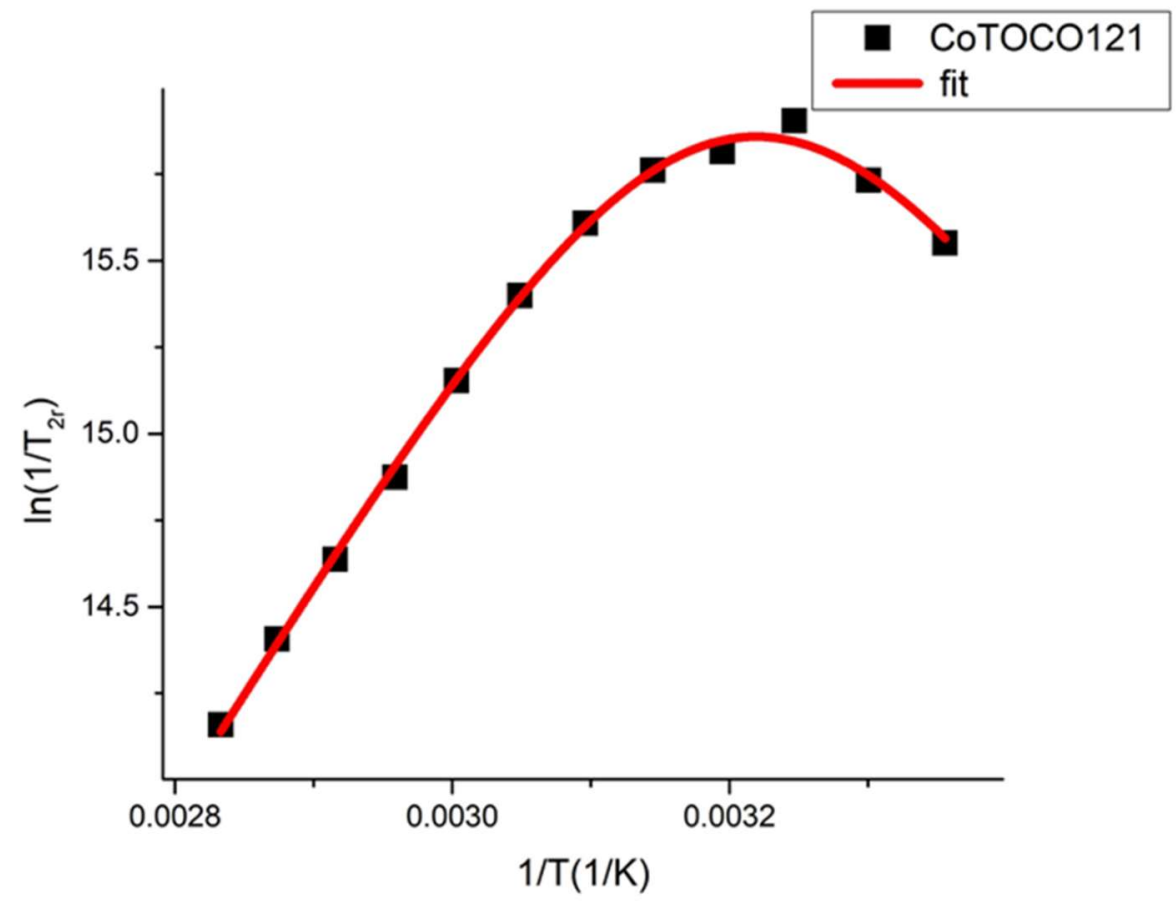

Figure S13. Transverse ${ }^{17} \mathrm{O}$ relaxivity, $\ln \left(1 / \mathrm{T}_{2 r}\right)$ as a function of temperature at $9.4 \mathrm{~T}$ for $\mathrm{Co}(\mathrm{TOCO} 121)$ in water at $\mathrm{pH}$ 7. Solid lines represent fit of the data. 


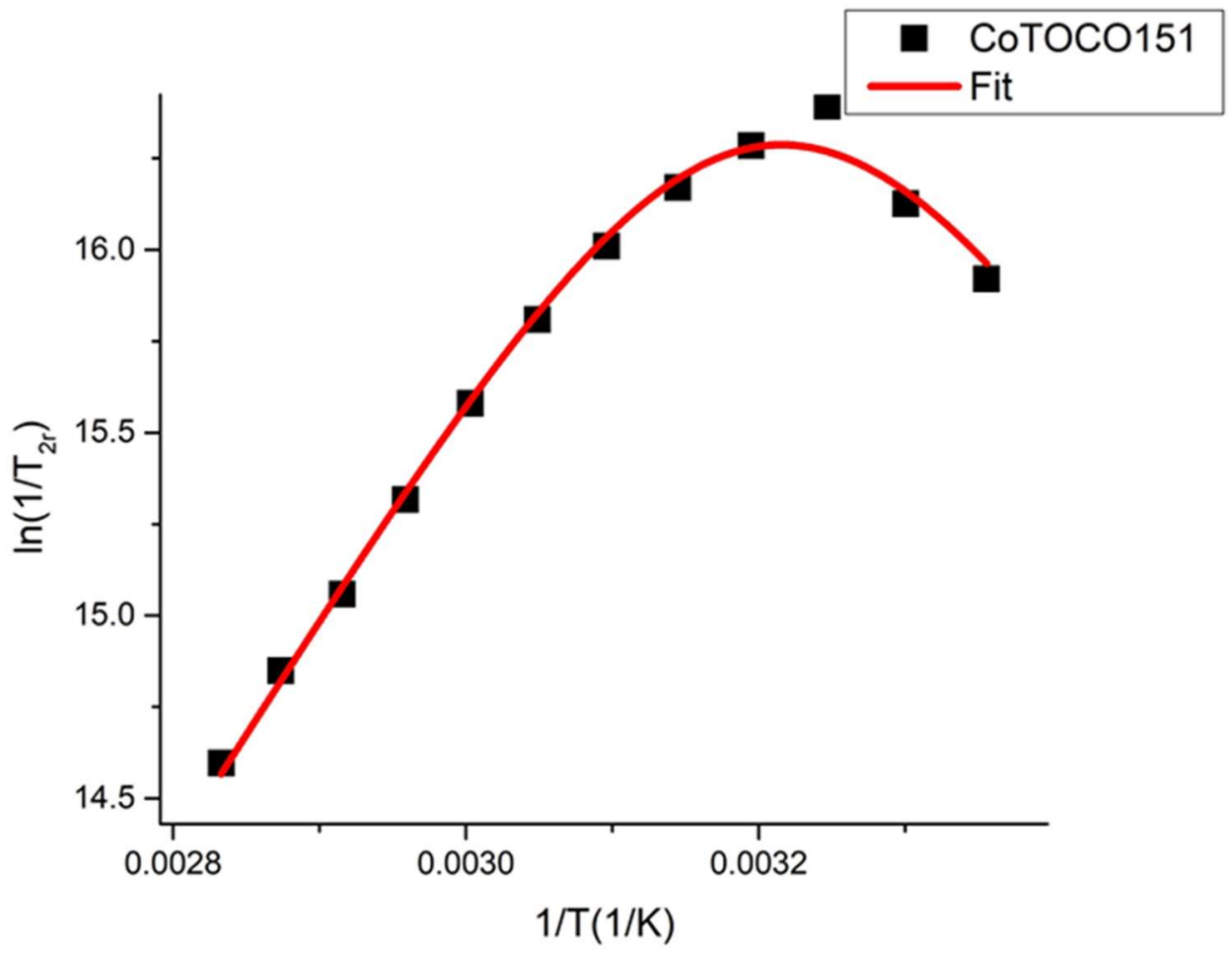

Figure S14. Transverse ${ }^{17} \mathrm{O}$ relaxivity, $\ln \left(1 / \mathrm{T}_{2 \mathrm{r}}\right)$ as a function of temperature at $9.4 \mathrm{~T}$ for $\mathrm{Co}$ (TOCO151) in water at $\mathrm{pH}$ 7. Solid lines represent fit of the data.

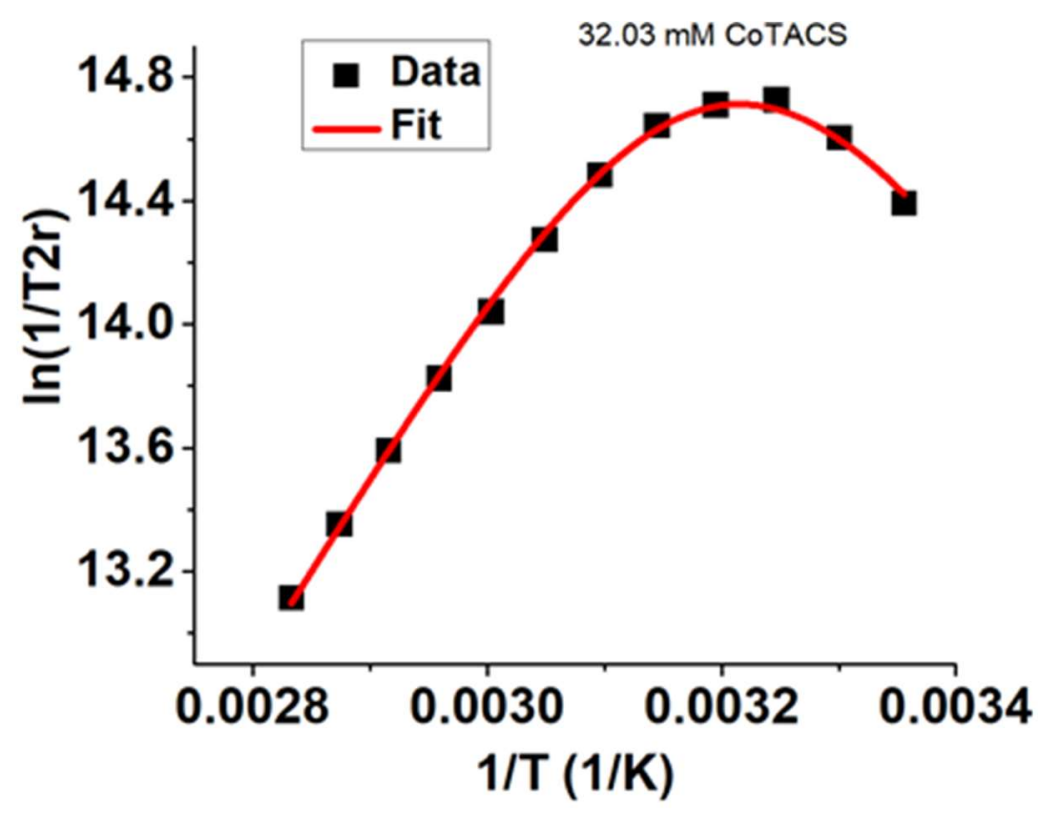

Figure S15. Transverse ${ }^{17} \mathrm{O}$ relaxivity, $\ln \left(1 / \mathrm{T}_{2 r}\right)$ as a function of temperature at $9.4 \mathrm{~T}$ for Co(TACs) in water at $\mathrm{pH} 6$. Solid lines represent fit of the data. 
Table S8. Rate parameters of various Co(II) complexes calculated from fitting the data of transverse relaxation rates at variable temperatures to swift-Connick equations.

\begin{tabular}{|c|c|c|c|c|}
\hline Complex & $K_{e x}^{298}\left(x 10^{6}\right) s^{-1}$ & $\Delta \mathrm{H}^{\ddagger} \mathrm{kJ} / \mathrm{mol}$ & $\Delta \mathrm{S}^{\ddagger} \mathrm{J} / \mathrm{mol} . \mathrm{K}$ & $C\left(\times 10^{8}\right)$ \\
\hline $\begin{array}{c}\text { Co(TOCs) } \\
\text { pH } 6\end{array}$ & 4.14 & $39.5 \pm 1.7$ & $14.4 \pm 5.7$ & $27.4 \pm 10.7$ \\
\hline $\begin{array}{c}\mathrm{Co}(\mathrm{TOCO} 121) \\
\mathrm{pH} 7\end{array}$ & 6.78 & $44.6 \pm 1.3$ & $35.4 \pm 4.3$ & $48.0 \pm 1.5$ \\
\hline $\begin{array}{c}\mathrm{Co}(\mathrm{TOCO} 121) \\
\mathrm{pH} 3.4\end{array}$ & 0.12 & $46.1 \pm 2.2$ & $19.1 \pm 7.4$ & $4.1 \pm 0.2$ \\
\hline $\begin{array}{c}\mathrm{Co}(\mathrm{TOCO} 151) \\
\mathrm{pH} 7\end{array}$ & 61.5 & $-56.1 \pm 0.6$ & $-283 \pm 1.9$ & $73.7 \pm 1.7$ \\
\hline $\begin{array}{c}\mathrm{Co}(\mathrm{TACs}) \\
\mathrm{pH} 6\end{array}$ & 2.16 & $42.9 \pm 0.9$ & $20.3 \pm 3.1$ & $15.3 \pm 0.3$ \\
\hline
\end{tabular}

Table S9. Slope of ${ }^{1} \mathrm{H}$ NMR water shift for $\mathrm{Co}(\mathrm{II})$ complexes at $37{ }^{\circ} \mathrm{C}$ at (a) $\mathrm{pH} 4$ and (b) pH 7.2. The shift was corrected for bulk magnetic susceptibility effects

\begin{tabular}{|ccc|}
\hline Complex & $\begin{array}{c}\text { Slope at pH 4 } \\
(\mathbf{p p m} / \mathrm{M})\end{array}$ & $\begin{array}{c}\text { Slope at pH 7.2 } \\
(\mathrm{ppm} / \mathrm{M})\end{array}$ \\
\hline CoTOCO151 & 2.4 & 11. \\
\hline CoTOCs & 5.0 & 15. \\
\hline CoTOCO121 & 0 & 12. \\
\hline
\end{tabular}


(a)

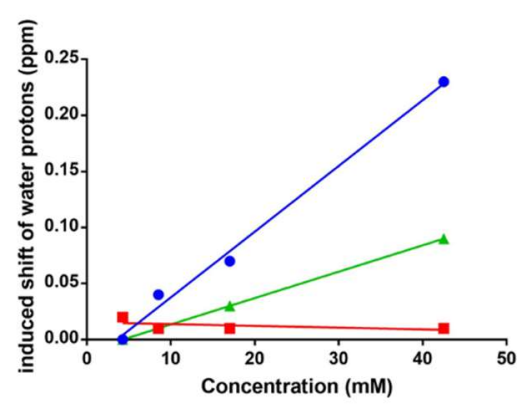

(b)

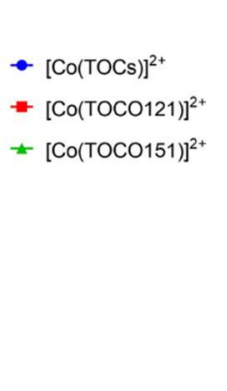

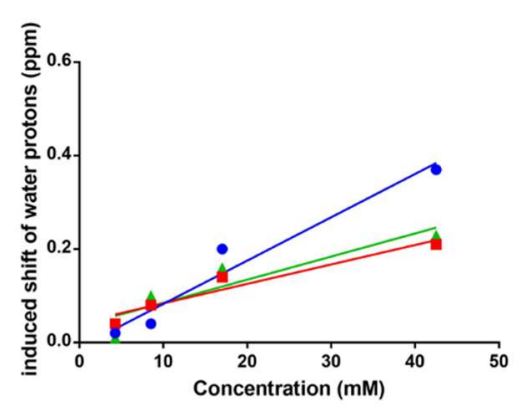

- $[\mathrm{Co}(\mathrm{TOCS})]^{2+}$

$-[\mathrm{Co}(\mathrm{TOCO} 121)]^{2+}$

$\Rightarrow[\mathrm{Co}(\mathrm{TOCO} 151)]^{2+}$

Figure S16. Plot of the ${ }^{1} \mathrm{H}$ NMR water shift for Co(II) complexes at $37^{\circ} \mathrm{C}$ at (a) pH 4 and (b) pH 7.2. The shift was corrected for bulk magnetic susceptibility effects.

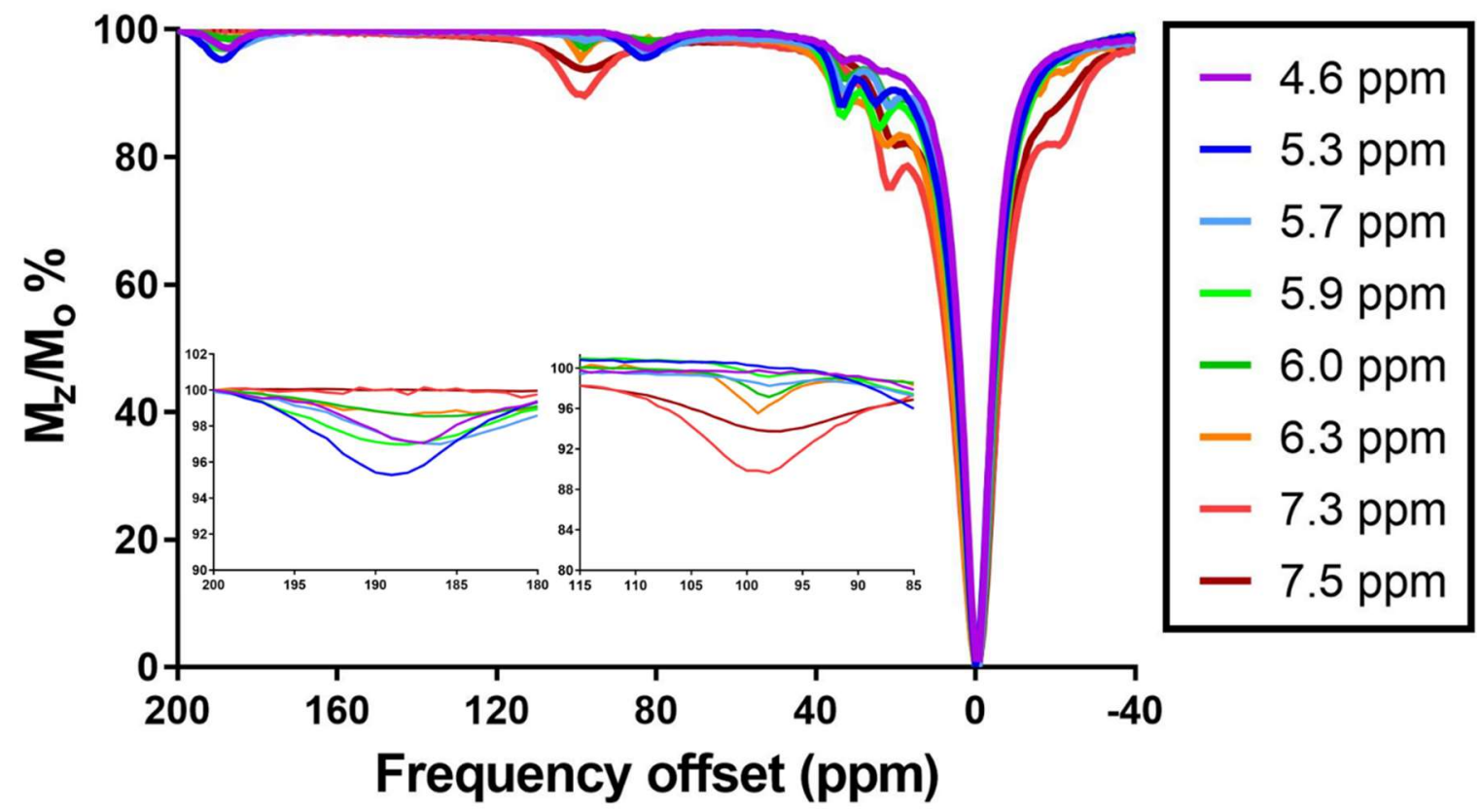

Figure S17. CEST spectra of Co(TOCs) at $37{ }^{\circ} \mathrm{C}$ showing pH-dependence. Samples contained 20 mM Co(TOCs), 20 mM buffer MES, 100 mM NaCl with B1 = $1000 \mathrm{~Hz}(24 \mu \mathrm{T}$ ) applied for 2s. 


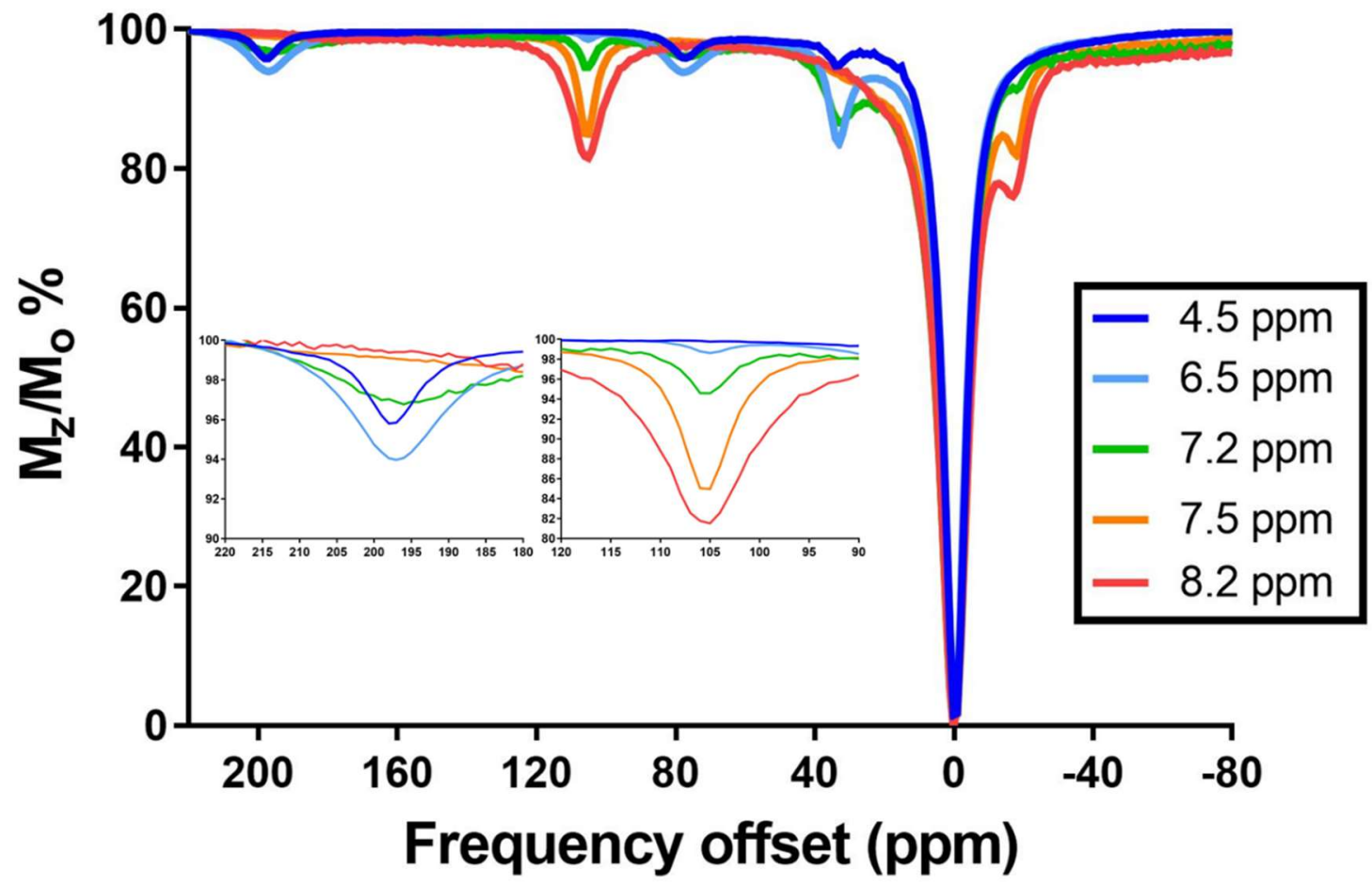

Figure S18. CEST spectra of Co(TOCO121) at $37{ }^{\circ} \mathrm{C}$ showing $\mathrm{pH}$-dependence. Samples contained $20 \mathrm{mM}$ Co(TOCO121), $20 \mathrm{mM}$ buffer MES, $100 \mathrm{mM} \mathrm{NaCl}$ with B1 = $1000 \mathrm{~Hz}(24 \mu \mathrm{T})$ applied for $2 \mathrm{~s}$. 


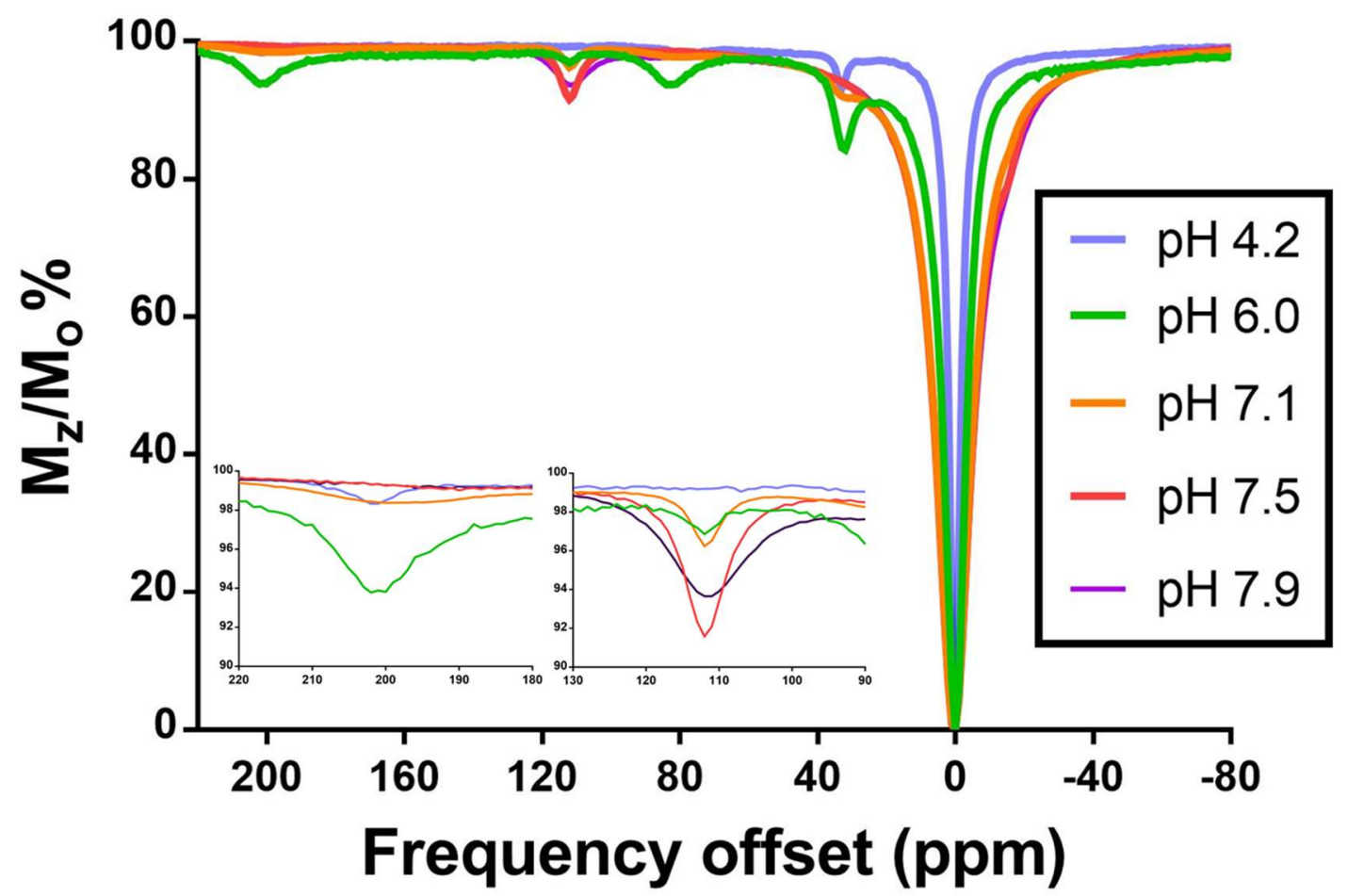

Figure S19. CEST spectra of Co(TOCO151) at $37{ }^{\circ} \mathrm{C}$ showing pH-dependence. Samples contained $20 \mathrm{mM}$ Co(TOCO151), $20 \mathrm{mM}$ buffer MES, $100 \mathrm{mM} \mathrm{NaCl}$ with B1 = $1000 \mathrm{~Hz}(24 \mu \mathrm{T}$ ) applied for $2 \mathrm{~s}$.

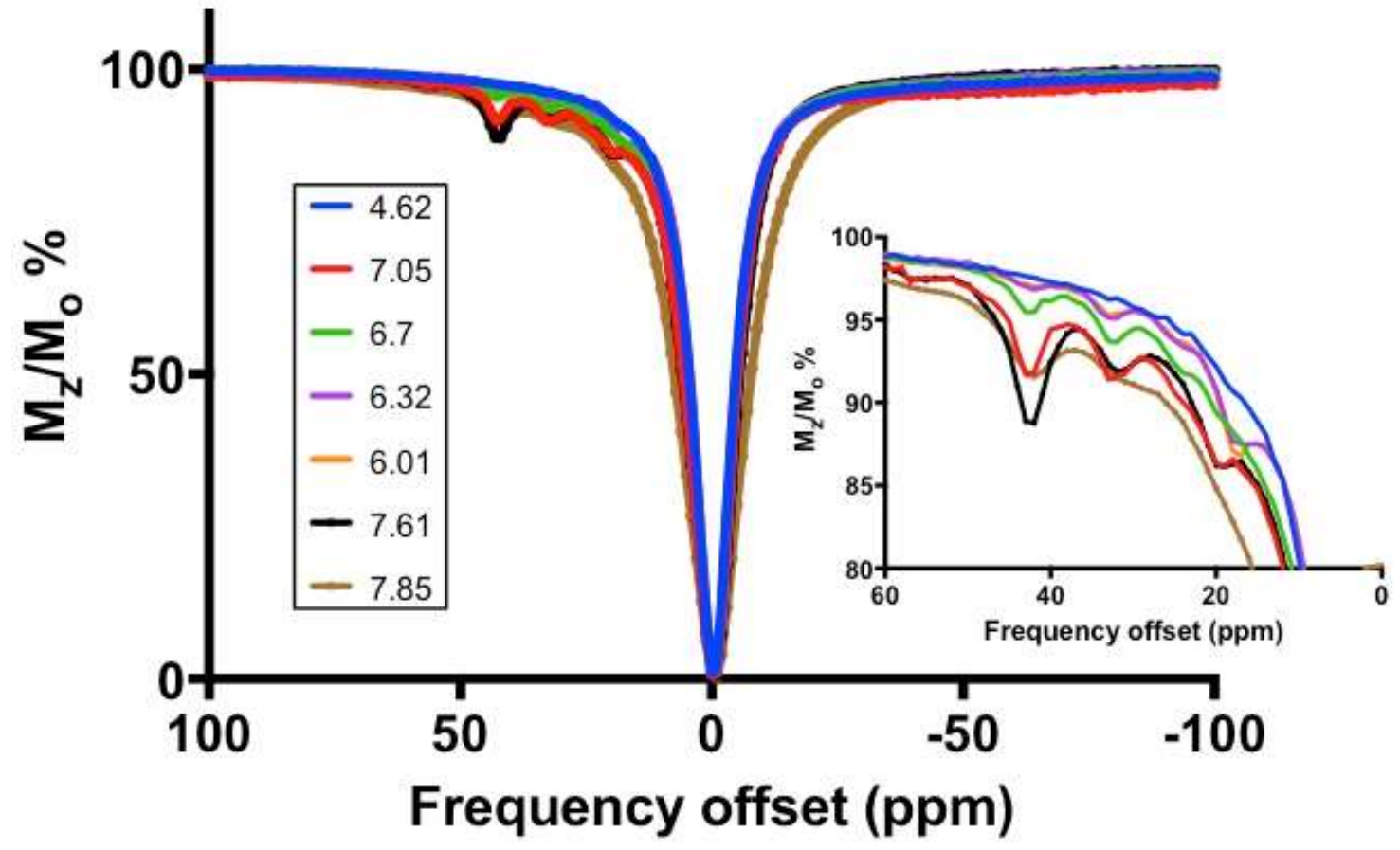

Figure S20. CEST spectra of Co(TACS) at $37{ }^{\circ} \mathrm{C}$ showing pH-dependence. Samples contained 20 mM Co(TACS), 20 mM buffer MES, $100 \mathrm{mM} \mathrm{NaCl}$ with $\mathrm{B}_{1}=1000 \mathrm{~Hz}(24 \mu \mathrm{T})$ applied for 2s. 
(a)

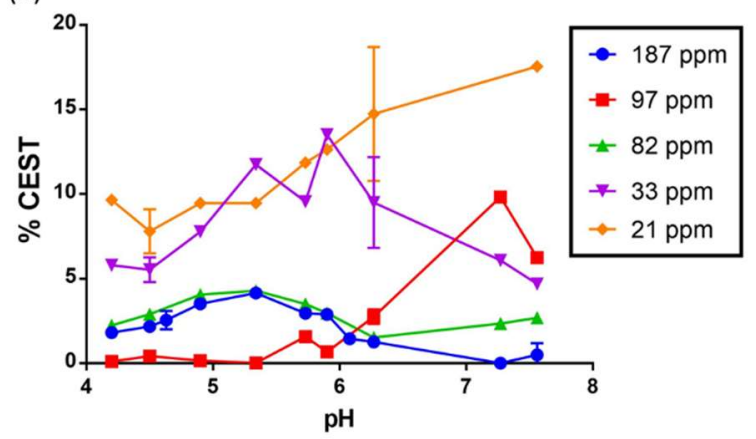

(b)

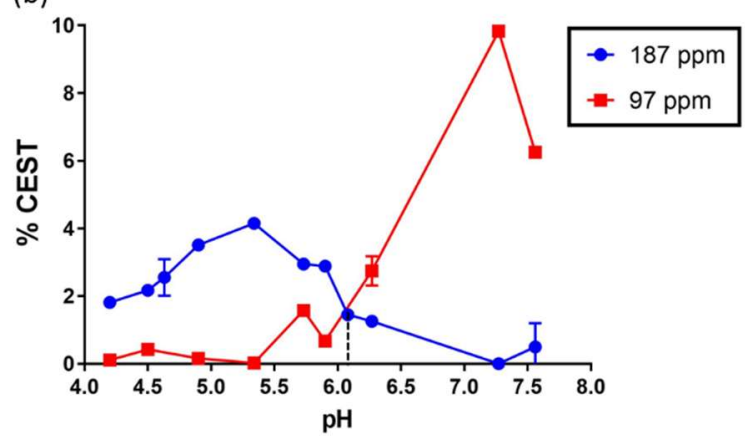

Figure S21. pH dependence of \% CEST in Co(TOCs) (a) all CEST peaks and (b) peaks at $187 \mathrm{ppm}$ and $97 \mathrm{ppm}$. Lines are drawn to more easily view the trend.

(a)

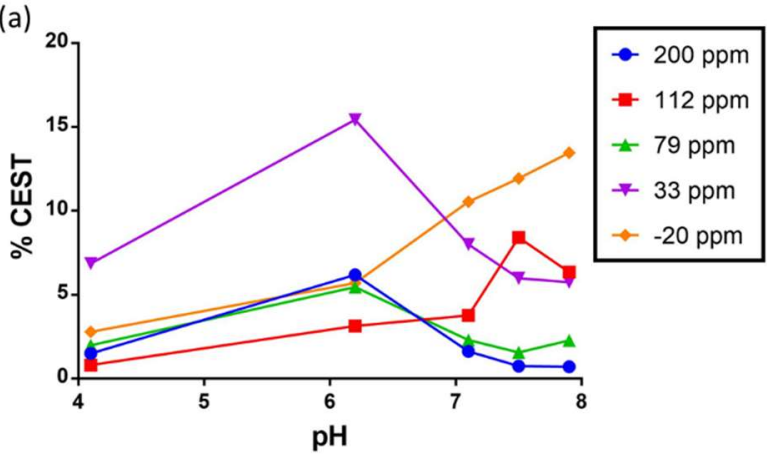

(b)

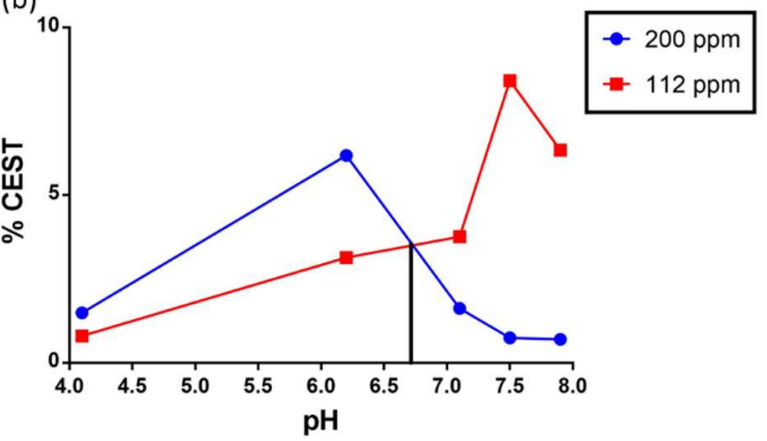

Figure S22. pH dependence of \% CEST in Co(TOCO151) (a) all CEST peaks and (b) peaks at 200 ppm and 112 ppm. Lines are drawn to more easily view the trend. 
Table S10. $\mathrm{pH}$ evolution of exchange rate constants calculated at $37^{\circ} \mathrm{C}$ for Co(TOCs) using Omega plot method. Samples contained $20 \mathrm{mM} \mathrm{Co(TOCs),} 20 \mathrm{mM}$ buffer MES, $100 \mathrm{mM} \mathrm{NaCl}$ with $\mathrm{B}_{1}=1000 \mathrm{~Hz}(24 \mu \mathrm{T})$ applied for 2s.

\begin{tabular}{|l|c|c|c|c|}
\hline pH & CEST peak & CEST \% & Kex $_{\text {(s }} \mathbf{- 1}^{\mathbf{1}}$ & Error \\
\hline $\mathbf{4 . 5}$ & 187 & 2.2 & 2800 & 1500 \\
\hline $\mathbf{4 . 9}$ & 187 & 3.5 & 3500 & 660 \\
\hline $\mathbf{5 . 3}$ & 187 & 4.1 & 3600 & 1700 \\
\hline \multicolumn{5}{|c|}{} \\
\hline pH & CEST peak & CEST \% & $\left.\mathbf{K}_{\text {ex }} \mathbf{( s}^{-\mathbf{1}}\right)$ & Error \\
\hline $\mathbf{4 . 5}$ & 82 & 2.8 & 1700 & 280 \\
\hline $\mathbf{4 . 9}$ & 82 & 4.1 & 2400 & 940 \\
\hline $\mathbf{5 . 3}$ & 82 & 4.3 & 3400 & 1400 \\
\hline $\mathbf{5 . 9}$ & 82 & 3.0 & 1100 & 130 \\
\hline
\end{tabular}

\begin{tabular}{|c|c|c|c|c|}
\hline $\mathbf{p H}$ & CEST peak & CEST \% & $\mathbf{K}_{\mathbf{e x}}\left(\mathbf{s}^{\mathbf{- 1}}\right)$ & Error \\
\hline $\mathbf{4 . 5}$ & 33 & 6.0 & 500 & 55 \\
\hline $\mathbf{4 . 9}$ & 33 & 7.8 & 500 & 10 \\
\hline $\mathbf{5 . 3}$ & 33 & 11.7 & 650 & 20 \\
\hline $\mathbf{5 . 9}$ & 33 & 13.5 & 1400 & 180 \\
\hline
\end{tabular}

\begin{tabular}{|c|c|c|c|c|}
\hline $\mathbf{p H}$ & CEST Peak & CEST \% & $\mathbf{K}_{\mathbf{e x}} \mathbf{( s}^{-\mathbf{1}} \mathbf{)}$ & Error \\
\hline $\mathbf{4 . 9}$ & 21 & 9.5 & 1500 & 120 \\
\hline $\mathbf{5 . 3}$ & 21 & 9.5 & 2100 & 410 \\
\hline $\mathbf{5 . 9}$ & 21 & 12.6 & 1400 & 75 \\
\hline $\mathbf{7 . 3}$ & 21 & 17.5 & 1300 & 320 \\
\hline
\end{tabular}

\begin{tabular}{|c|c|c|c|c|}
\hline $\mathbf{p H}$ & CEST Peak & CEST \% & $\mathbf{K}_{\mathbf{e x}} \mathbf{( s}^{-\mathbf{1}} \mathbf{)}$ & Error \\
\hline $\mathbf{6 . 1}$ & 97 & 3.0 & 3700 & 70 \\
\hline $\mathbf{7 . 3}$ & 97 & 9.8 & 3300 & 770 \\
\hline $\mathbf{7 . 6}$ & 97 & 6.2 & 3600 & 66 \\
\hline
\end{tabular}


Table S11. pH evolution of exchange rate constants at $37{ }^{\circ} \mathrm{C}$ for $\mathrm{Co}(\mathrm{TOCO} 121)$. Samples contained $20 \mathrm{mM}$ Co(TOCO121), $20 \mathrm{mM}$ buffer MES, $100 \mathrm{mM} \mathrm{NaCl}$ with $\mathrm{B}_{1}=1000 \mathrm{~Hz}(24 \mu \mathrm{T})$ applied for $2 \mathrm{~s}$.

\begin{tabular}{|c|c|c|c|c|}
\hline pH & CEST peak & CEST \% & $\left.\mathbf{K}_{\mathbf{e x}} \mathbf{( s}^{-\mathbf{1}}\right)$ & Error \\
\hline $\mathbf{4 . 5}$ & 197 & 4.1 & 1500 & 411 \\
\hline $\mathbf{6 . 5}$ & 197 & 6.0 & 3800 & 510 \\
\hline $\mathbf{7 . 2}$ & 197 & 3.1 & 3200 & 1300 \\
\hline
\end{tabular}

\begin{tabular}{|c|c|c|c|c|}
\hline pH & CEST peak & CEST \% & Kex $\left._{\text {(s }} \mathbf{- 1}\right)$ & Error \\
\hline $\mathbf{4 . 5}$ & 77 & 4.1 & 2100 & 950 \\
\hline $\mathbf{6 . 5}$ & 77 & 6.1 & 3200 & 1400 \\
\hline $\mathbf{7 . 2}$ & 77 & 3.9 & 2000 & 370 \\
\hline
\end{tabular}

\begin{tabular}{|c|c|c|c|c|}
\hline pH & CEST peak & CEST \% & $\mathbf{K}_{\text {ex }} \mathbf{( s}^{-\mathbf{1}} \mathbf{)}$ & Error \\
\hline $\mathbf{4 . 5}$ & 33 & 4.7 & 790 & 220 \\
\hline $\mathbf{6 . 5}$ & 33 & 16 & 1300 & $<10$ \\
\hline $\mathbf{7 . 2}$ & 33 & 13 & 2100 & 220 \\
\hline
\end{tabular}

\begin{tabular}{|c|c|c|c|c|}
\hline pH & CEST peak & CEST \% & $\mathbf{K}_{\mathbf{e x}} \mathbf{( s}^{-\mathbf{1}} \mathbf{)}$ & Error \\
\hline $\mathbf{6 . 5}$ & 105 & 1.4 & 820 & 70 \\
\hline $\mathbf{7 . 2}$ & 105 & 16 & 590 & 30 \\
\hline
\end{tabular}

Table S12. pH evolution of exchange rate constants at $37^{\circ} \mathrm{C}$ for $\mathrm{Co}(\mathrm{TOCO} 151)$. Samples contained $20 \mathrm{mM} \mathrm{Co(TOCO151),} 20 \mathrm{mM}$ buffer MES, $100 \mathrm{mM} \mathrm{NaCl}$ with $\mathrm{B}_{1}=1000 \mathrm{~Hz}(24 \mu \mathrm{T})$ applied for $2 \mathrm{~s}$.

\begin{tabular}{|c|c|c|c|c|}
\hline pH & CEST peak & CEST \% & $\mathbf{K}_{\text {ex }}\left(\mathbf{s}^{-\mathbf{1}}\right)$ & Error \\
\hline $\mathbf{7 . 0}$ & 200 & 1.6 & 1300 & 670 \\
\hline
\end{tabular}

\begin{tabular}{|c|c|c|c|c|}
\hline pH & CEST peak & CEST \% & $\mathbf{K}_{\mathbf{e x}} \mathbf{( s}^{\mathbf{- 1}} \mathbf{)}$ & Error \\
\hline $\mathbf{7 . 0}$ & 112 & 3.8 & 620 & 80 \\
\hline $\mathbf{7 . 5}$ & 112 & 8.4 & 1200 & 80 \\
\hline $\mathbf{7 . 9}$ & 112 & 6.4 & 2500 & 480 \\
\hline
\end{tabular}




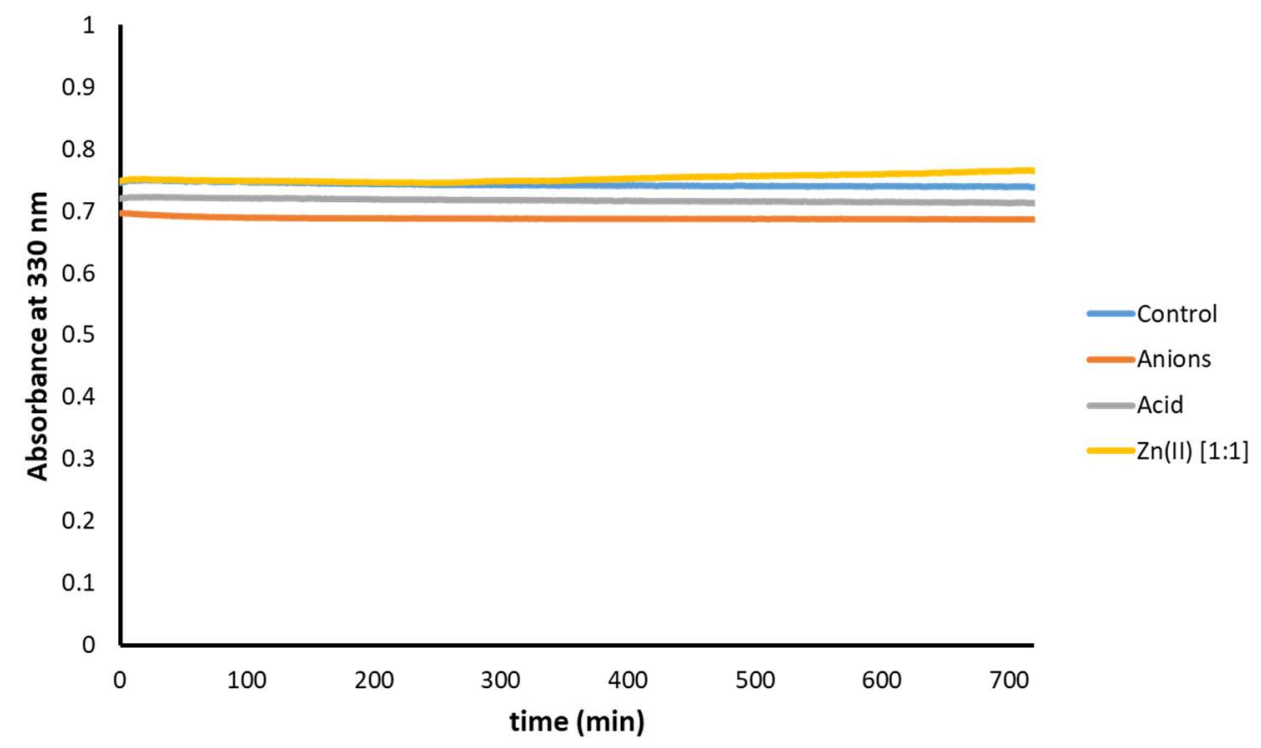

Figure S23. The plot of absorbance versus time of solutions containing $50 \mu \mathrm{M}$ Co(TOCs) in (a) 20

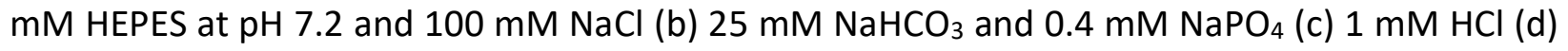
1 equivalent of $\mathrm{ZnCl}_{2}$ at $37^{\circ} \mathrm{C}$ was monitored at $330 \mathrm{~nm}$.

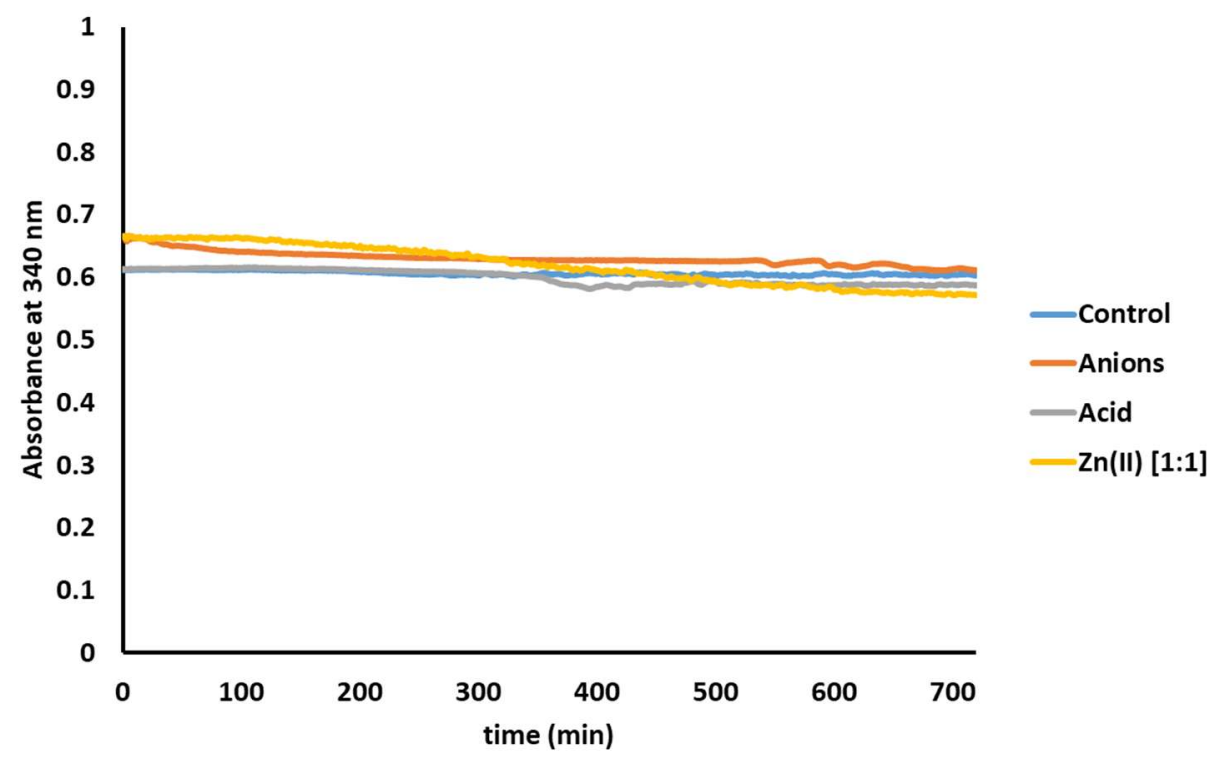

Figure S24. The plot of absorbance versus time of solutions containing $50 \mu \mathrm{M}$ Co(TOCO121) in (a) $20 \mathrm{mM} \mathrm{HEPES}$ at pH 7.2 and $100 \mathrm{mM} \mathrm{NaCl}$ (b) $25 \mathrm{mM} \mathrm{NaHCO}_{3}$ and $0.4 \mathrm{mM} \mathrm{NaPO}_{4}$ (c) $1 \mathrm{mM}$ $\mathrm{HCl}$ (d) 1 equivalent of $\mathrm{ZnCl}_{2}$ at $37^{\circ} \mathrm{C}$ was monitored at $340 \mathrm{~nm}$. 


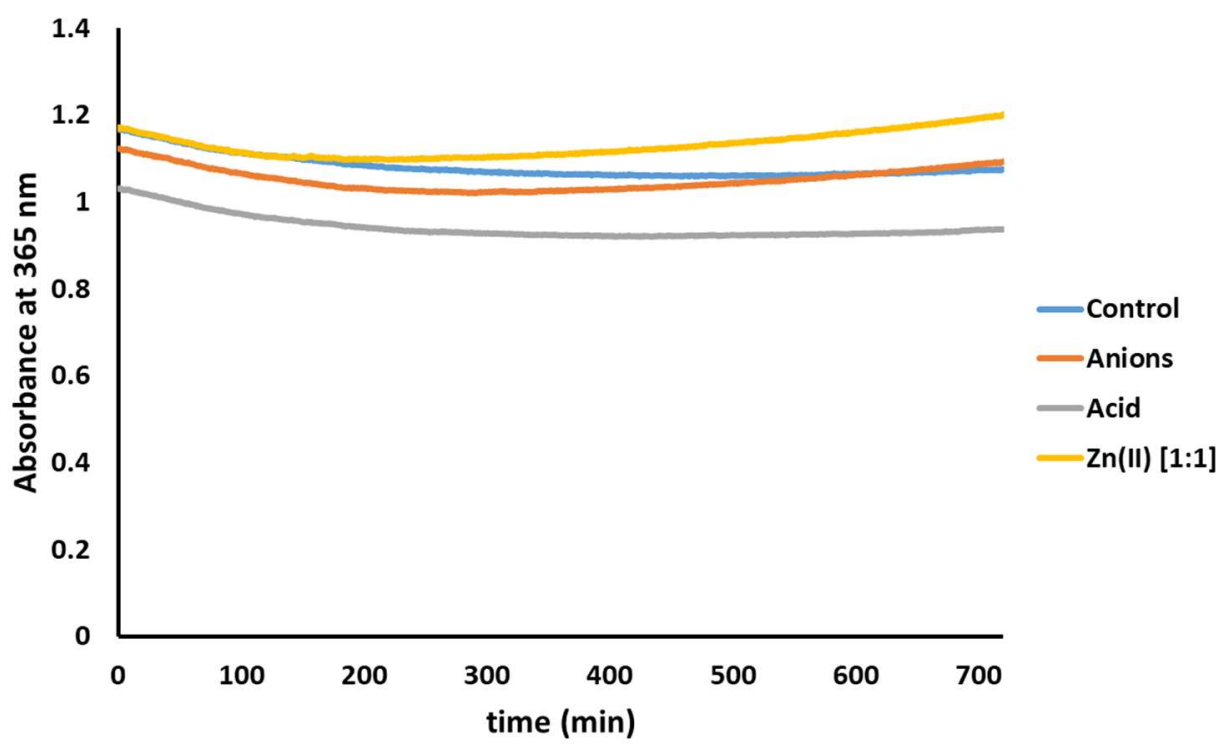

Figure S25. The plot of absorbance versus time of solutions containing $50 \mu \mathrm{M}$ Co(TOCO151) in (a) $20 \mathrm{mM} \mathrm{HEPES}$ at pH 7.2 and $100 \mathrm{mM} \mathrm{NaCl}$ (b) $25 \mathrm{mM} \mathrm{NaHCO}_{3}$ and $0.4 \mathrm{mM} \mathrm{NaPO}_{4}$ (c) $1 \mathrm{mM}$ $\mathrm{HCl}$ (d) 1 equivalent of $\mathrm{ZnCl}_{2}$ at $37^{\circ} \mathrm{C}$ was monitored at $365 \mathrm{~nm}$.

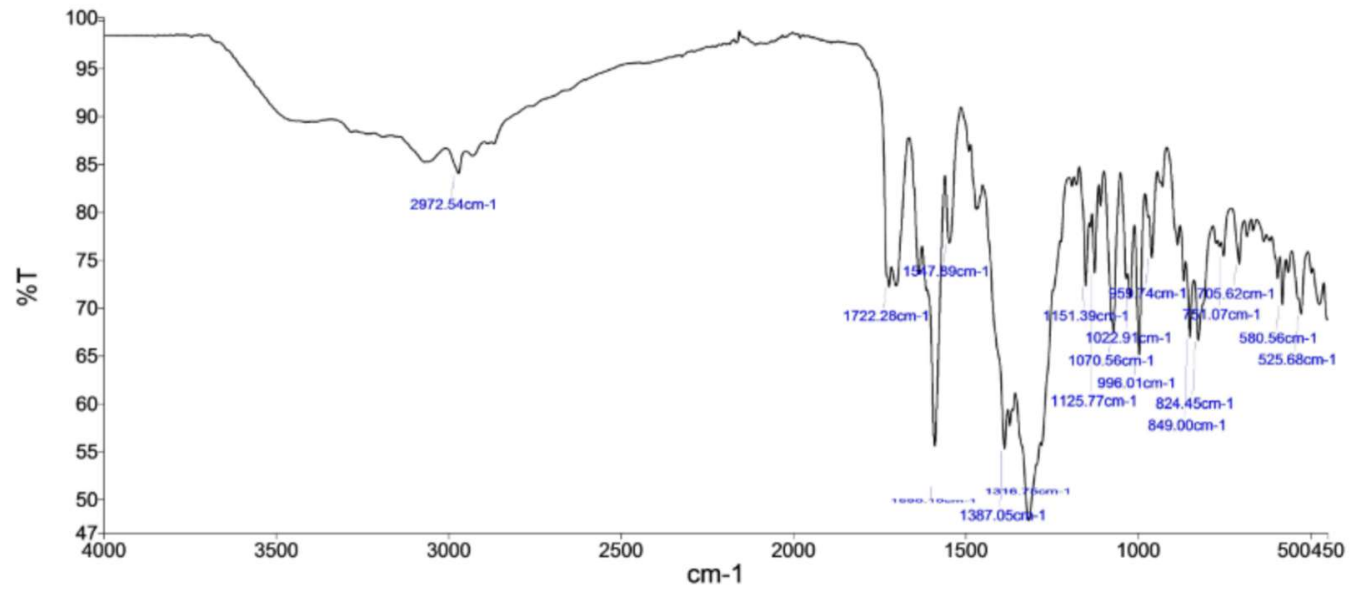

Figure S26. Solid state FT-IR spectrum of Co(TOCO121) 


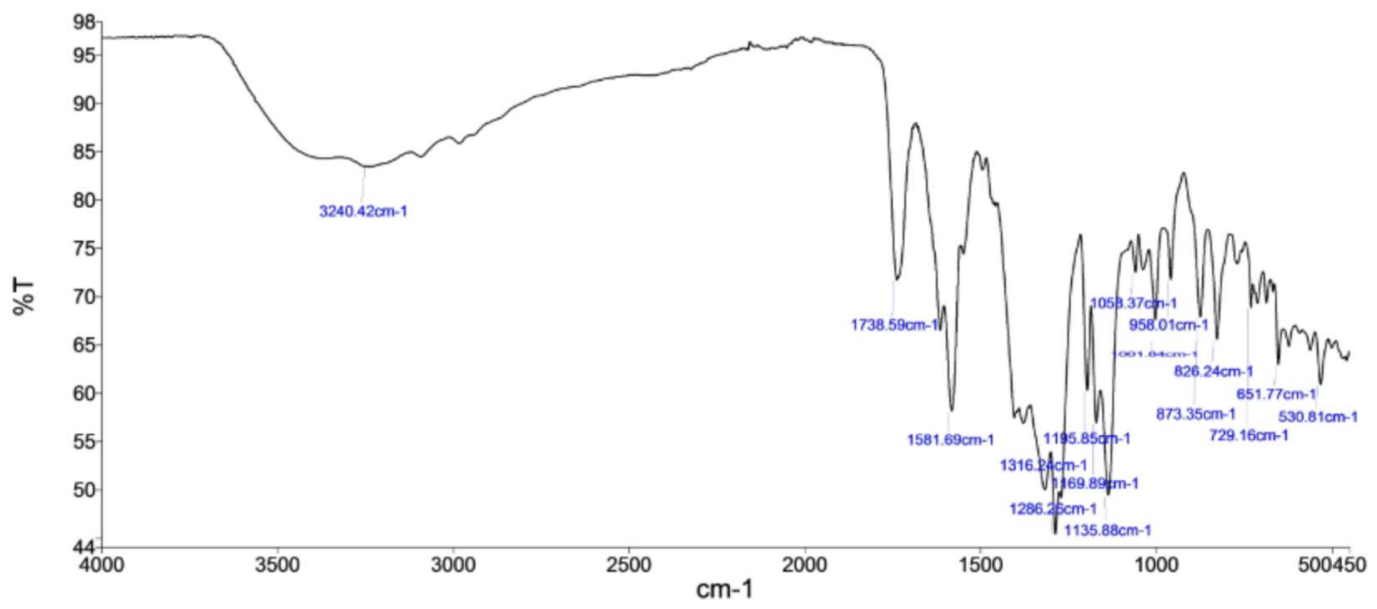

Figure S27. Solid state FT-IR spectrum of Co(TOCO151)

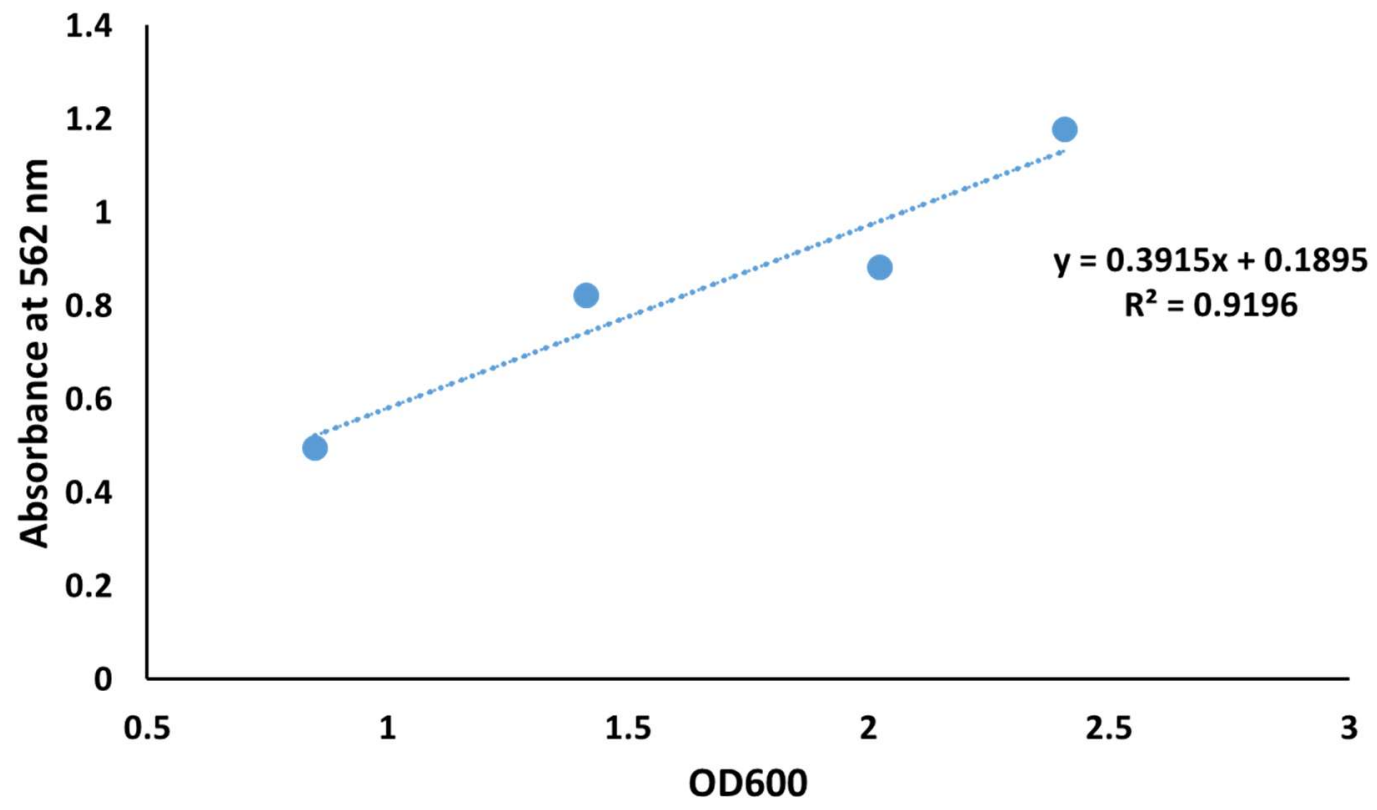

Figure S28. Plot of the total protein content measured by Pierce protein assay vs optical density at $600 \mathrm{~nm}$ in S. cerevisiae in midlog phase. 
(a) Control
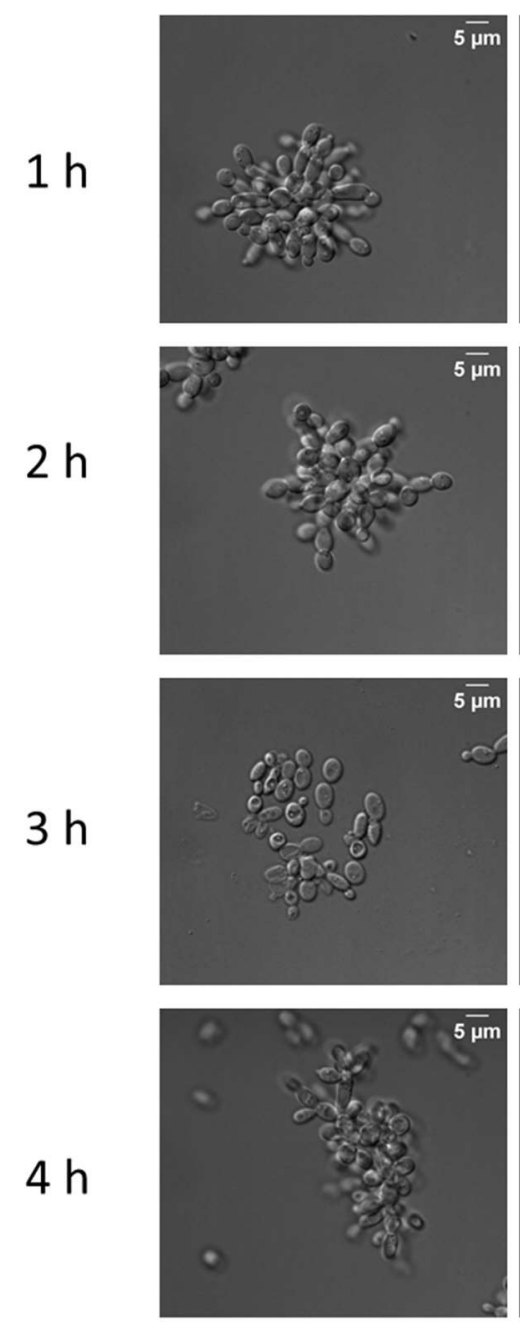
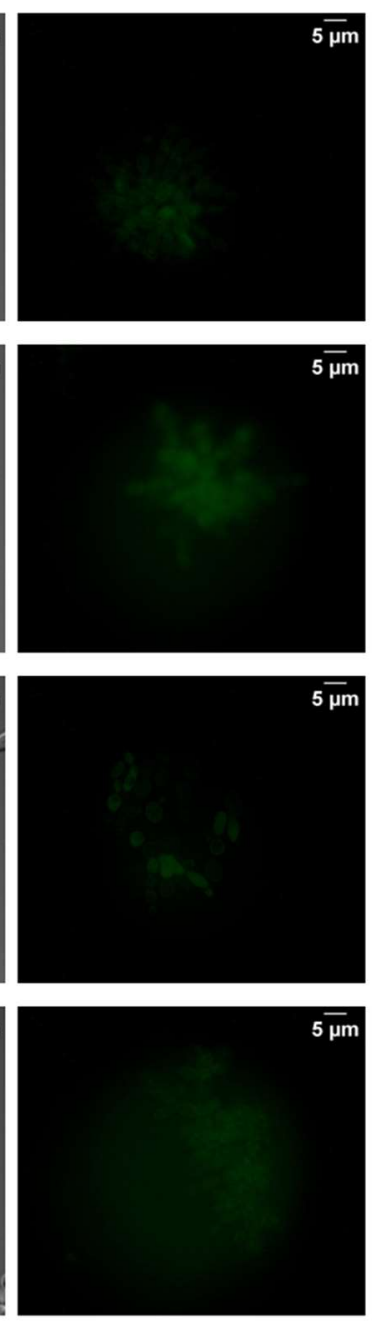

(b) $[\mathrm{Co}(\mathrm{TOCO} 151)]\left(\mathrm{NO}_{3}\right)_{2}$
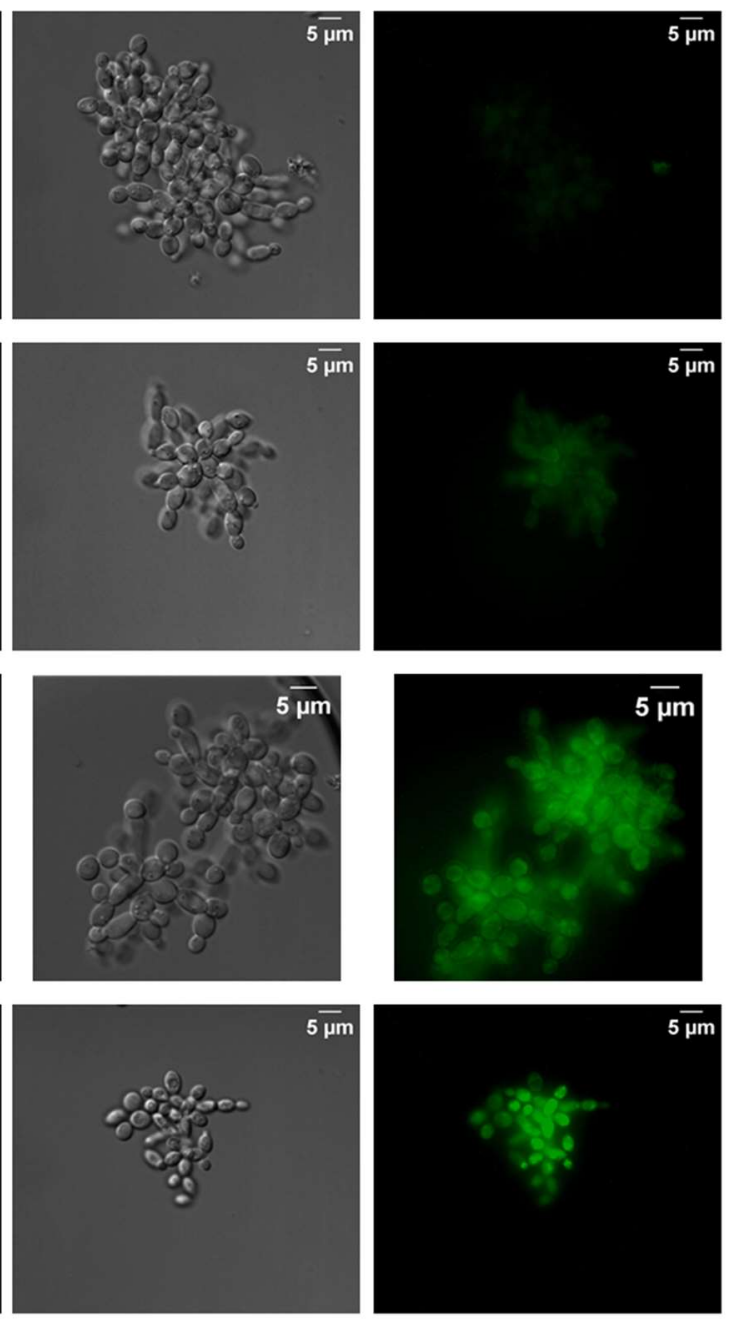

Figure S29. Fluorescence microscopy images of S. cerevisiae PC538 cells. (a) Heat treated control cells (b) Co(TOCO151) (50mM) treated heat treated cells. Cells were examined after incubations for the times indicated. Excitation $(470 \mathrm{~nm})$ emission $(509 \mathrm{~nm})$. All examples show fluorescence with $5 \mu \mathrm{M}$ scale and exposure $2.8 \mathrm{~s}$. 


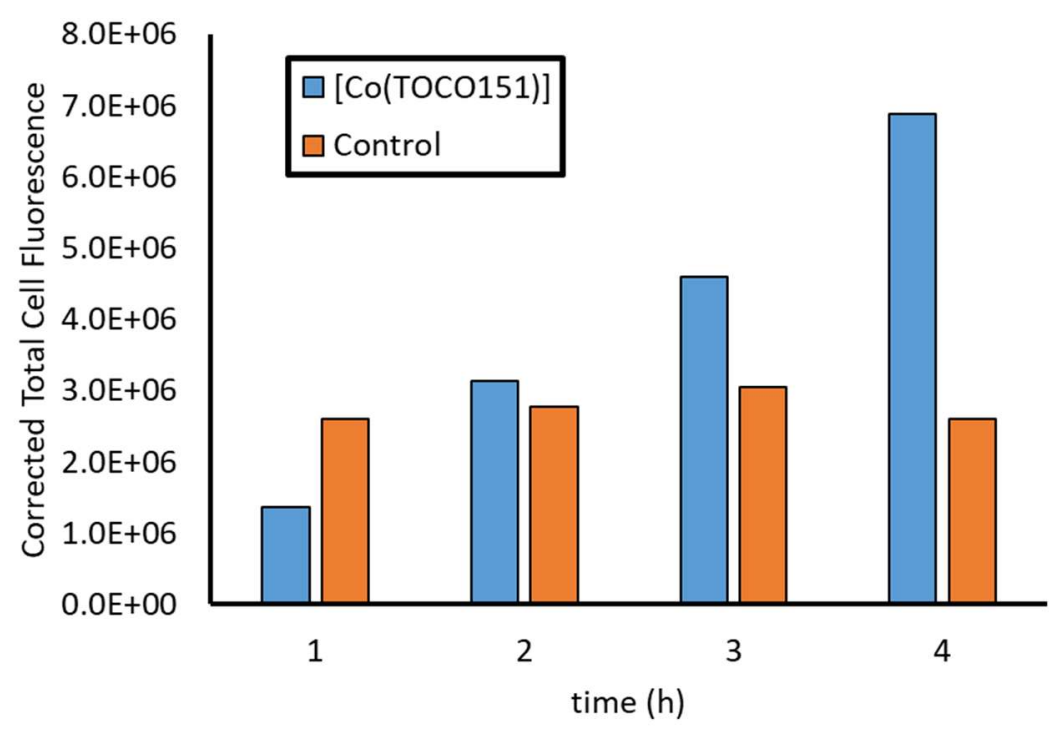

Figure S30. Time evolution of corrected total cell fluorescence intensity of S. cerevisiae PC538 cells. (a) Heat treated control cells (b) Co(TOCO151) (50mM) treated heat treated cells with time.

YEPD

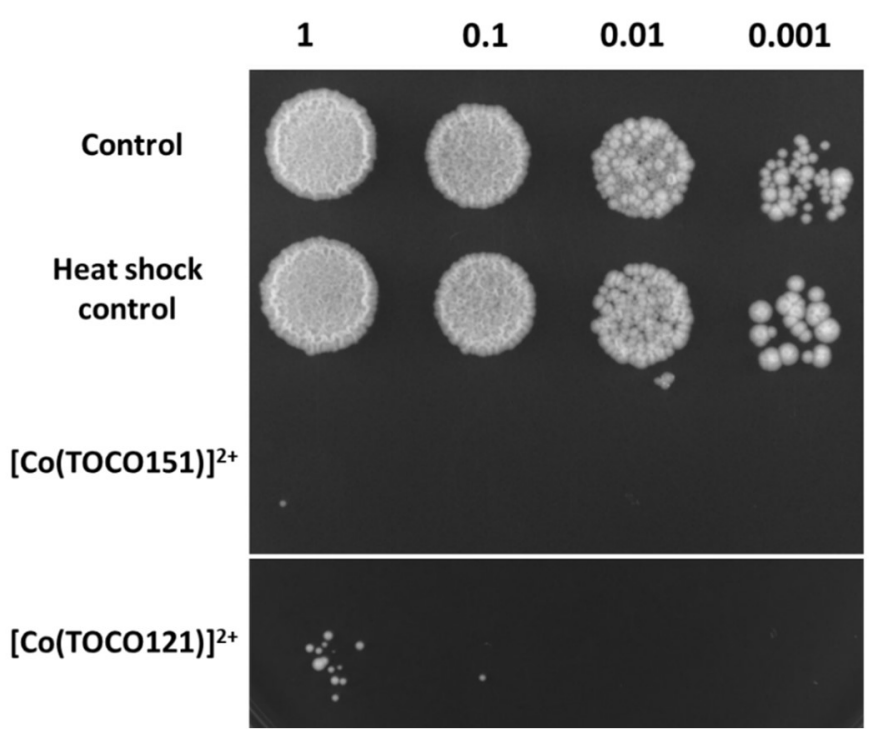

YEPD

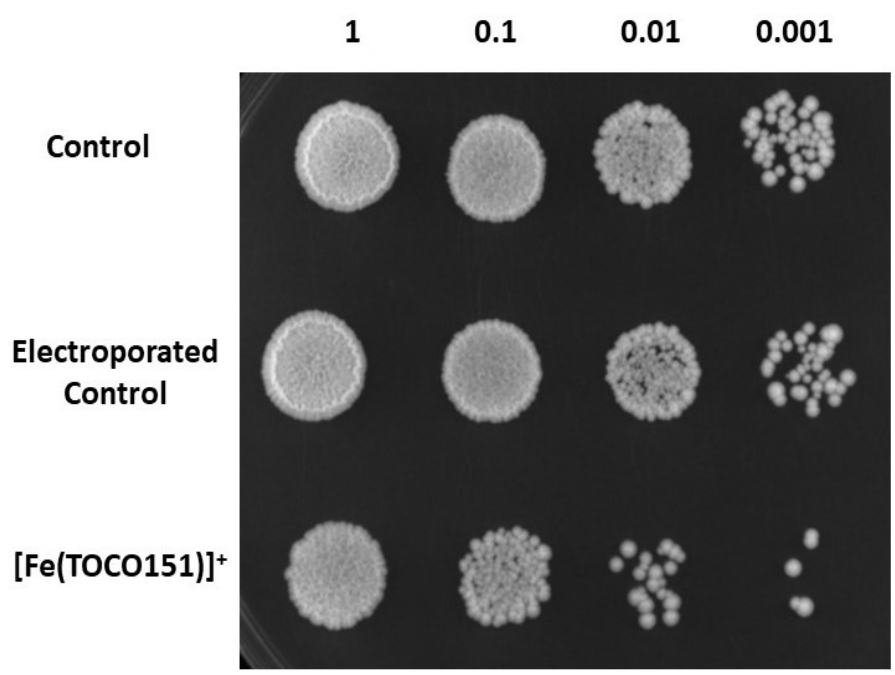

Figure S44. Serial dilution of S. cerevisiae PC538 cells to test cell viability. Left: control cells, heat treated control cells, $50 \mathrm{mM}$ Co(TOCO151) and heat treated and $50 \mathrm{mM} \mathrm{Co(TOCO121)} \mathrm{and} \mathrm{heat}$ treated cells were spotted in serial dilutions on YEPD media at $30^{\circ} \mathrm{C}$. Right: comparison with an analogous Fe(III) complex that has a smaller effect on viability of S. cerevisiae PC538. (Iron data was adapted from J. Inorg. Biochem. 2019, 201, 110832). 